\title{
Ray-Tracing-Based Modeling of Clad-Removed Step-Index Plastic Optical Fiber in Smart Textiles: Effect of Curvature in Plain Weave Fabric
}

\author{
Sun Hee Moon, ${ }^{1}$ Joon Seok Lee ${ }^{D}{ }^{2},{ }^{2}$ and In Hwan Sul $\mathbb{D I}^{1}$ \\ ${ }^{1}$ Department of Materials Design Engineering, Kumoh National Institute of Technology, Gumi 39177, Republic of Korea \\ ${ }^{2}$ Department of Fiber System Engineering, Yeungnam University, Gyungsan 38541, Republic of Korea
}

Correspondence should be addressed to Joon Seok Lee; leejs@ynu.ac.kr; In Hwan Sul; inhwan.sul@gmail.com

Received 30 August 2017; Accepted 19 December 2017; Published 29 March 2018

Academic Editor: Charles C. Sorrell

Copyright ( 2018 Sun Hee Moon et al. This is an open access article distributed under the Creative Commons Attribution License, which permits unrestricted use, distribution, and reproduction in any medium, provided the original work is properly cited.

Plastic optical fiber was chosen for information delivery media in smart textile. Cladding layer was peeled off by chemical and mechanical methods to find optimal peeling conditions. Both radial side illumination and longitudinal end-tip illumination were measured for visible light of $627 \mu \mathrm{m}$ wavelength. A half-cone-shaped jig was manufactured using 3D printing to give various curvature conditions to fibers. Also POFs were embedded in plain weave textile structure to measure the light dissipation effect. The waveguide phenomenon was modeled using discrete ray tracing technique and ray-to-interface collision detection algorithm. Results from the proposed modeling technique showed linear relationship with those from experiment.

\section{Introduction}

Technology fusion has been an issue for the last decade. Among various approaches in $6 \mathrm{~T}$ fusion, smart fabric or smart textile seems to be the hottest theme in textile area. The idea of smart textile is to assign additional functionality to garments with IT materials. The new functionality includes not only simple sensing of external environment such as stress/strain [1,2], temperature [3], or humidity [4], but also active response to the environment $[5,6]$. The most common materials used so far for smart textiles were basically conductive materials. They included metals [7], conductive polymers like polyacetylene [8], polyaniline [9], polypyrrole [10], PVDF [11], or semiconductors [12]. This approach used "electrons" as information delivery media.

The above-mentioned electron-based conductive materials have some cons, especially for textile application. Flexibility is the key component to consider for wearable computer. There are ongoing efforts to make a flexible conductive material such as organic light-emitting diodes (OLEDs) [13], graphene [14], graphene-silver nanowire (AgNW) [15], and metal- (Ag-) based nanofiber network [16] or to apply conductive coating like metals like aluminum [17] or single-walled carbon nanotube (SWNT) to nonconductive material surface [18]. Nevertheless, there exists a gap between research and application yet.

We changed the point of view and focused on other type of information delivery media, "light." Light can deliver multiple number of wavelengths simultaneously, which is the reason why glass optical fiber (GOF) is widely used for telephone and high-speed Internet connection [19]. On the contrary, the high bending stiffness of GOF limits it use in textile application. Instead, plastic optical fiber (POF) seems to be better candidate for our new media, as it can provide fabric structure with both flexibility and light delivery capability. Our goal is to design an active light-emitting garment using POF. The end use can be different depending on the wavelength used. If visible light is used, the POFtextile hybrid structure can be a new kind of fashion item. Otherwise, if ultraviolet light [20] is used, it can be selfsterilized cushions or pillows (Figure 1(a)). Furthermore, light harvesting garment can be thought of (Figure 1(b)). By the way, conventional POF has cylindrical shape and delivers light tip-to-tip direction only. We removed some area of the 


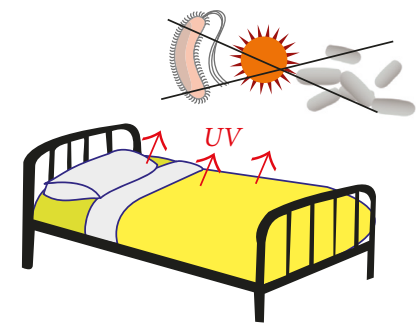

(a)

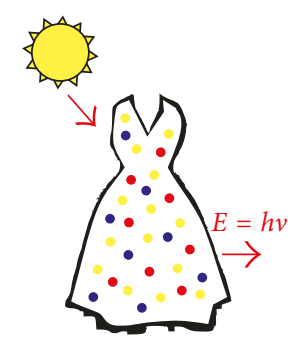

(b)

FIGURe 1: Possible applications of POF-based smart textile. (a) Light-delivery textile (self-sterilizing garment); (b) light-harvesting textile (images reproduced from http://www.google.com)

POF cladding layer by mechanical or chemical treatment to facilitate the textile-thickness-direction light delivery. The light delivery efficiency using the treated POF was modeled theoretically and measured experimentally.

\section{Literature Review}

Prior art documents were reviewed in both modeling and experimental aspects.

The modeling technique of light transfer in optical fiber, generally known as waveguide theory, was already established in the 1970s. The waveguide theory dealt with mostly rectangular or circular cross-sections [21], which sufficed for GOF or optical devices. And the wavelength of interest was $1550 \mathrm{~nm}$, where the material dispersion is minimized in silica glass [19]. Layers of optical fiber, that is, cladding and core, can have constant (step-index) or nonconstant (gradient-index) level of refractive index [21]. Even if GOF had simple geometry of cylindrical shape, light transfer inside the GOF had to be calculated by solving complex differential equation [22]. Meanwhile, POF has different working range of wavelength, that is, 400 700 $\mathrm{nm} \mathrm{[23],} \mathrm{and}$ the high curvature makes it difficult to apply boundary condition in the differential equation. Ray tracing can be an alternative technique to predict light transfer if volumetric information of light delivered is only concerned, not detailed waveguide mode information. It assumes that light ray is a discrete series of vectors, and its course can be calculated by tracing the movement of each vector iteratively. Durana et al. used ray tracing to calculate bending loss dependency on POF cladding [24]. Also Lomer et al. used ray tracing to predict lateral polishing of bends in POF-based multipoint liquid-level measurement sensor [25]. But the previous papers still dealt with simple geometry only, and there have been few research on modeling of POF in complex structure like textile weave pattern. For general geometry, Barnhart developed an efficient ray tracing Mathematica ${ }^{\circledR}$ tool kit which can deal with even lenses or graded index fibers [26]. But the Mathematica software is based on exact calculation, and it performance is bounded by hardware specification, so the complex geometry of textile weave structure is difficult to apply.

There have also been numerous works on experimental aspects. Side-glowing optical fiber (SOF), in which intentionally inserted defects make Rayleigh scattering inside
TABle 1: Overall specification of POF specimens.

\begin{tabular}{lc}
\hline Type & Value \\
\hline Core material & PMMA \\
Core refractive index & 1.49 \\
Clad material & Fluorinated polymer \\
Clad refractive index & 1.41 \\
Refractive index profile & Step index \\
Numerical aperture & 0.50 \\
Acceptance angle & $60^{\circ}$ \\
Service temperature & $-55 \sim 70^{\circ} \mathrm{C}$ \\
\hline
\end{tabular}

TABLE 2: Detailed dimensions of three types of POF specimens.

\begin{tabular}{lcc}
\hline Name & \multicolumn{2}{c}{ Diameter $(\mu \mathrm{m})$} \\
\hline PGR-FB250 & Core & Clad \\
PGR-FB750 & 240 & 250 \\
PGR-FB1000 & 735 & 750 \\
\hline
\end{tabular}

the core, was used in clinical [27], or photocatalytic [28] applications. It was widely commercialized, but the con is that the direction and position of defects cannot be controlled by end users. Meanwhile, slanted fiber Bragg grating (sFBG) is more elegant way of fabric-thickness-direction light delivery. In sFBG, gratings with constant intervals tilts incident light out of the fiber longitudinal axis [29]. Zhao et al. [30] and Jáuregui et al. [31] used sFBG for temperature sensor and interrogation unit, respectively. sFBG can react to very specific range of wavelength, and the tilting angle can be controlled by adjusting the grating inclination. But the high price of grating imprinting device and process is bottleneck for commercialization. As textile products have generally low range of customer price compared with that of high-tech IT devices, we need a method with reasonable manufacturing price, yet maintaining efficiency and controllability in light delivery. Therefore, this paper used an alternative approach that claddings of POF were peeled off locally and light was delivered through the damaged region. In this way, the direction of light leakage could be easily controlled, and the amount of light delivered could be modeled efficiently with computational techniques. 


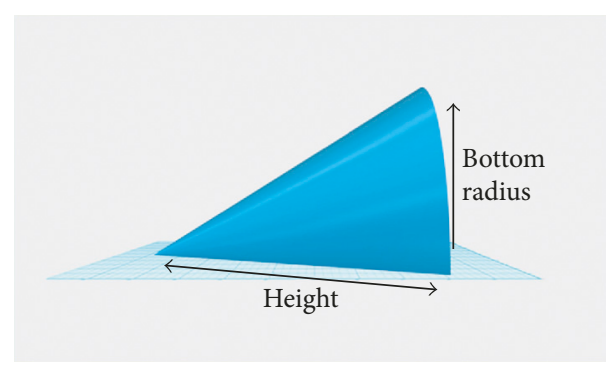

(a)

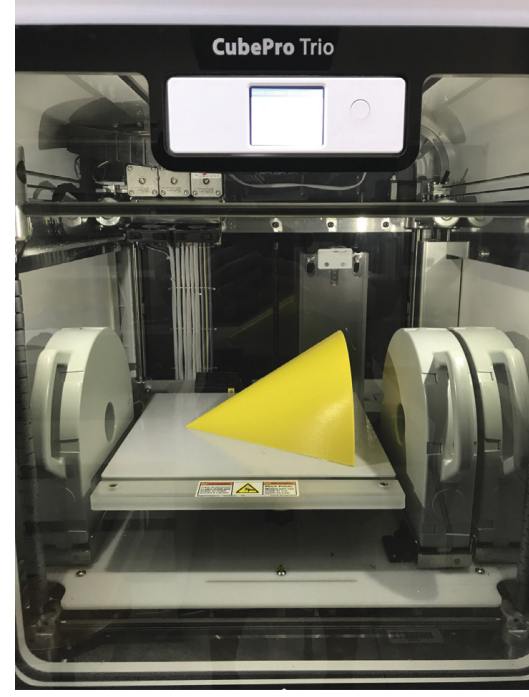

(b)

Figure 2: Half-cone-shaped curvature measurement jig preparation (cone height: $198 \mathrm{~mm}$; bottom radius: $124 \mathrm{~mm}$ ). (a) Half-cone design using Autodesk 123D. (b) 3D printed jig.

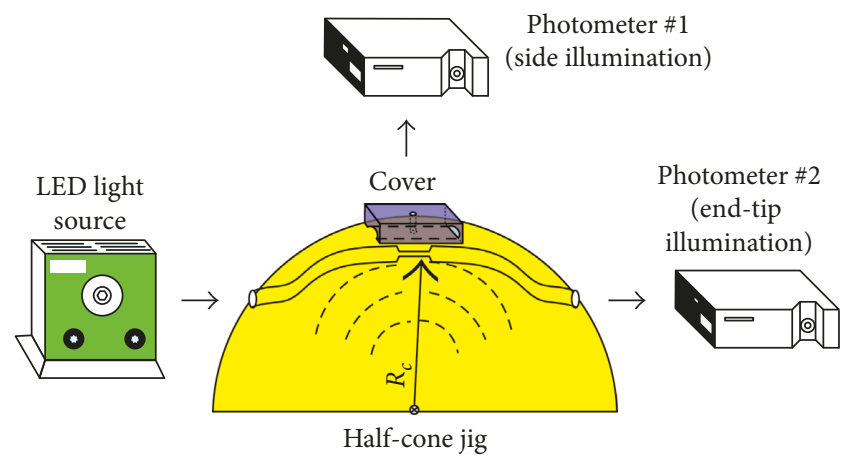

(a)

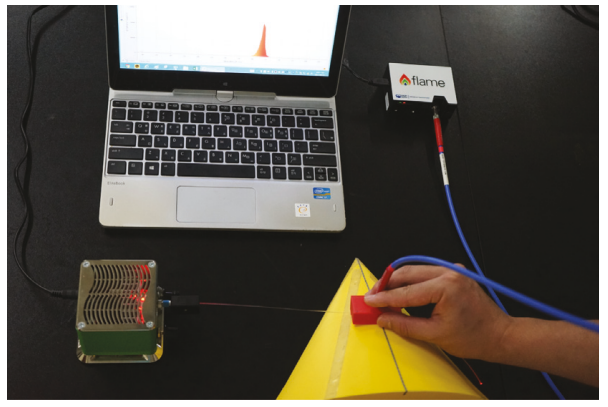

(b)

Figure 3: Light intensity measurement for a single fiber with a half-cone jig. (a) System configuration of half-cone jig test. (b) Experiment screenshot.

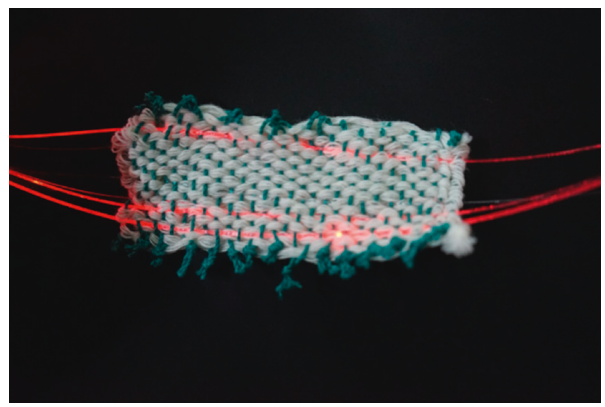

FIGURE 4: Light intensity measurement of a fiber inserted within plain weave textile. 


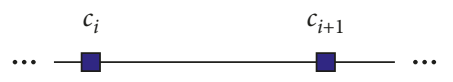

(a)

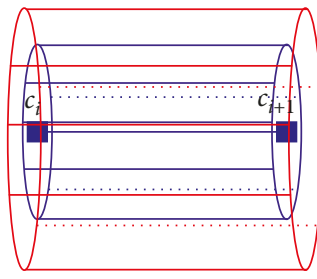

(b)

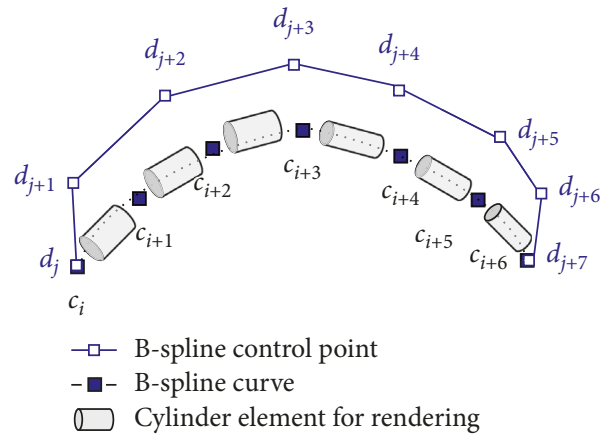

(c)

Figure 5: Hollow-cylinder-shaped fiber model for virtual half-cone simulation. (a) Initial center points for fiber longitudinal central axis. (b) Hollow-cylindrical shape assigned for each center point pair. (c) Deformation of fiber using cantilever beam analogy.

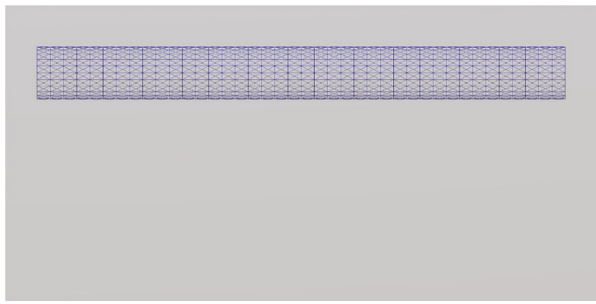

(a)

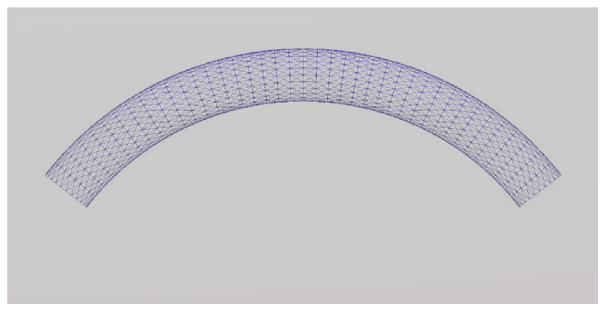

(c)

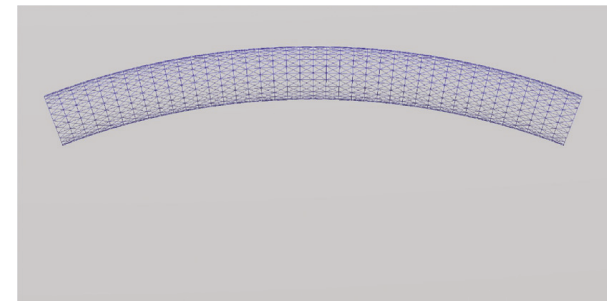

(b)

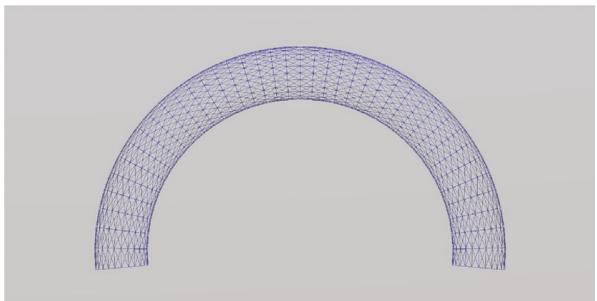

(d)

FiguRE 6: Curvature expression using the cylindrical mesh model ( $R_{c}=$ radius of curvature; fiber length $L=5 \mathrm{~mm}$ ). (a) $R_{c}=\infty$. (b) $R_{c}=6.7 \mathrm{~mm}$. (c) $R_{c}=2.8 \mathrm{~mm}$. (d) $R_{c}=1.7 \mathrm{~mm}$.

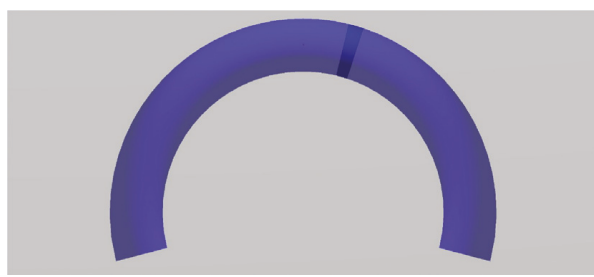

(a)

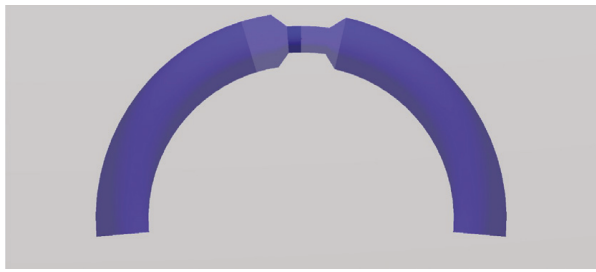

(c)

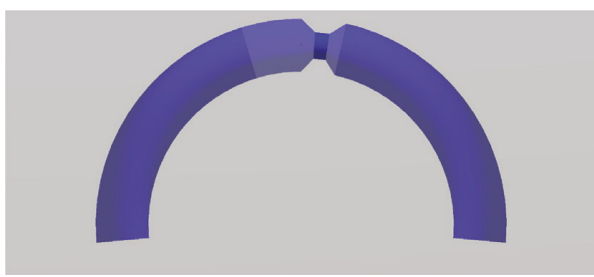

(b)

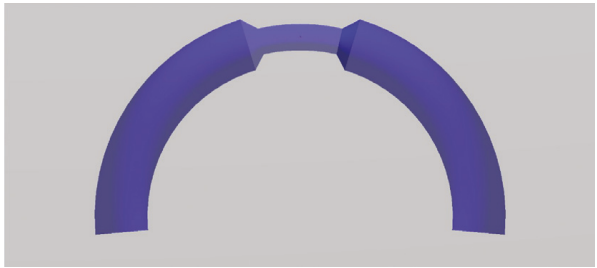

(d)

FiguRE 7: Example of virtual clad-removal operation (when $R_{c}=1.7 \mathrm{~mm}$ and $L=5 \mathrm{~mm}$ ). (a) Step 0. (b) Step 1. (c) Step 2 . (d) Step 3. 


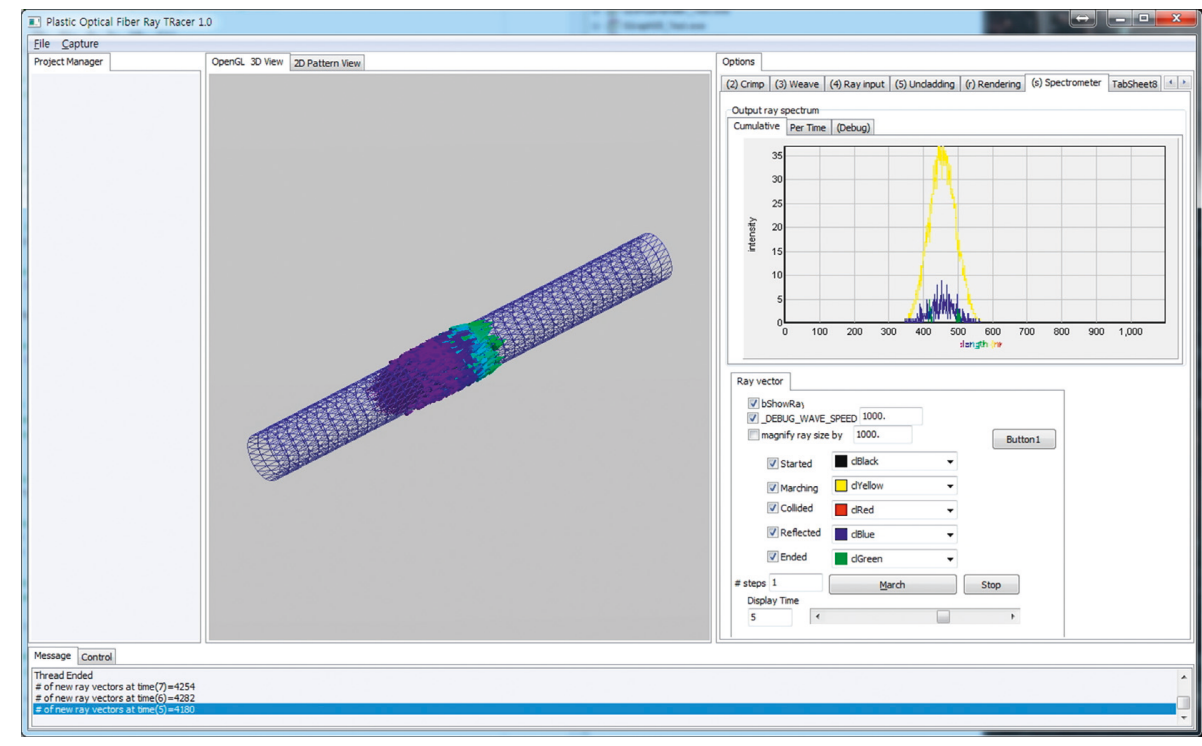

FIGURE 8: Screenshot of modeling software interface and ray vector marching (note that the vectors were temporarily exaggerated in length by 1000 times for demonstrational purpose).

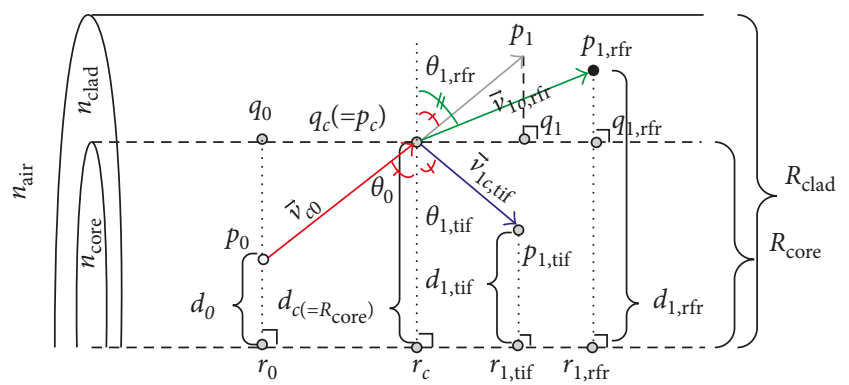

Figure 9: Schematic view of ray-tracing version refraction model.

TABle 3: Detailed description of the parameters in Figure 9.

\begin{tabular}{lr}
\hline Parameter & Description \\
\hline$n_{\text {air }}, n_{\text {core }}, n_{\text {clad }}$ & Refractive index of air, core, and cladding, resp. \\
$R_{\text {core }}, R_{\text {clad }}$ & Radii of core and cladding \\
$\mathbf{p}_{0}$ & Start point of ray vector $x_{\omega, \tau}$ \\
$\mathbf{p}_{c}$ & Ray-to-interface collision point \\
$\mathbf{p}_{1}$ & Ray end position when there is no refractive index \\
change & New position after refraction \\
$\mathbf{p}_{1, \mathrm{rfr}}$ & New position after total internal reflection (TIR) \\
$\mathbf{p}_{1, \mathrm{tif}}$ & Ray incidence angle to interface \\
$\theta_{0}$ & Ray angle after refraction/TIR \\
$\theta_{1, \mathrm{rfr}} \theta_{1, \mathrm{tif}}$ & Distance from $\mathbf{p}_{0}, \mathbf{p}_{c}, \mathbf{p}_{1}, \mathbf{p}_{1, \mathrm{rfr}}, \mathbf{p}_{1, \mathrm{rfr}}$ to fiber central \\
$d_{0}, d_{c}, d_{1}, d_{1, \mathrm{rfr}}, d_{1, \mathrm{rfr}}$ & axis, resp. \\
$\mathbf{r}_{0}, \mathbf{r}_{c}, \mathbf{r}_{1}, \mathbf{r}_{1, \mathrm{rfr}}, \mathbf{r}_{1, \mathrm{rfr}}$ & Nearest point from $\mathbf{p}_{0}, \mathbf{p}_{c}, \mathbf{p}_{1}, \mathbf{p}_{1, \mathrm{rfr}}, \mathbf{p}_{1, \mathrm{rfr}}$ to fiber \\
$\mathbf{q}_{0}, \mathbf{q}_{c}, \mathbf{q}_{1}, \mathbf{q}_{1, \mathrm{rfr}}, \mathbf{q}_{1, \mathrm{rfr}}$ & central axis, resp. \\
$\overrightarrow{\mathbf{v}}_{\mathrm{c} 0}, \overrightarrow{\mathbf{v}}_{1 \mathrm{c}, \mathrm{rfr}}, \overrightarrow{\mathbf{v}}_{01 \mathrm{c}, \mathrm{rfr}}$ & Nearest point from $\mathbf{p}_{0}, \mathbf{p}_{c}, \mathbf{p}_{1}, \mathbf{p}_{1, \mathrm{rfr}}, \mathbf{p}_{1, \mathrm{rfr}}$ to interface, \\
resp.
\end{tabular}




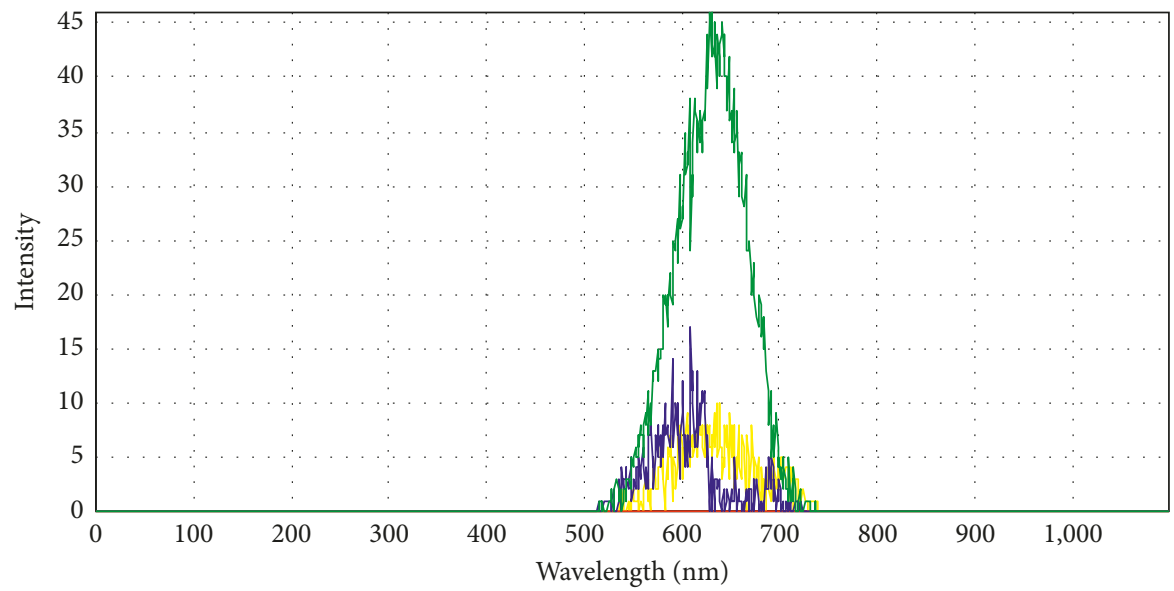

FIGURE 10: Screenshot of the light intensity measured during the simulation (yellow: marching rays; green: stopped rays; blue: refracted/reflected rays. Vertical axis is not scaled yet).

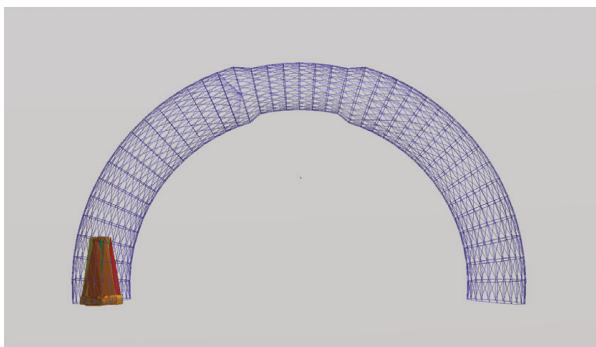

(a)

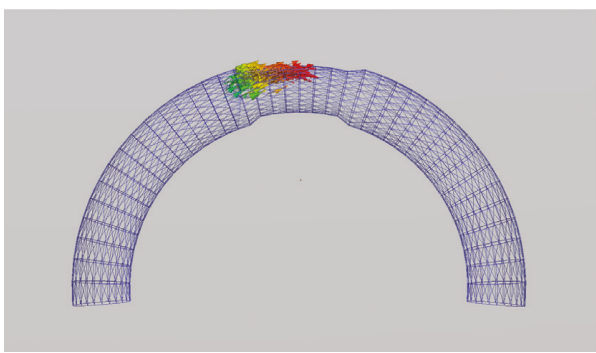

(c)

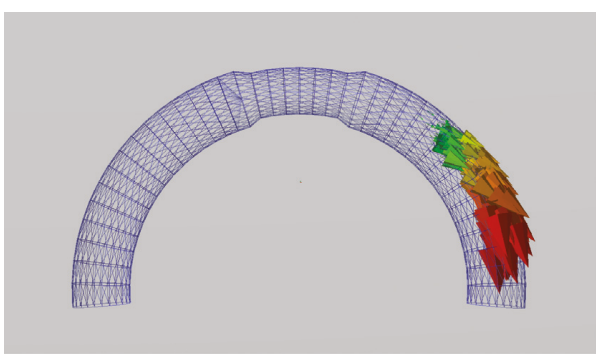

(e)

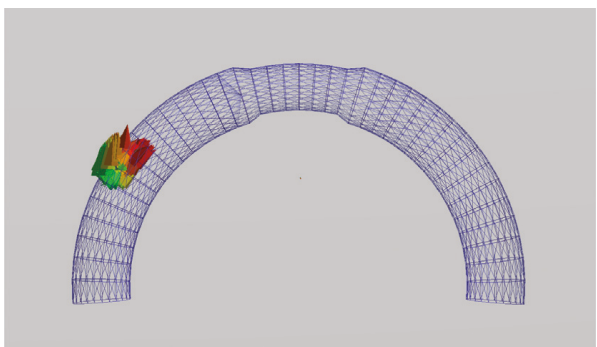

(b)

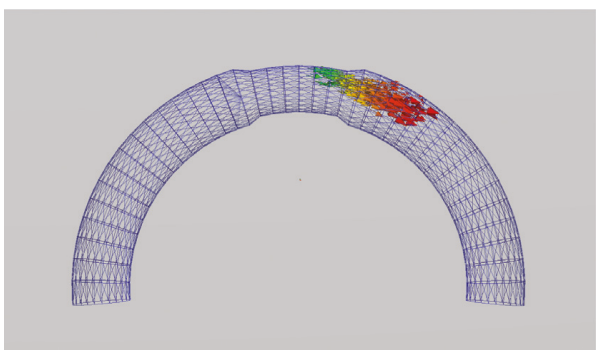

(d)

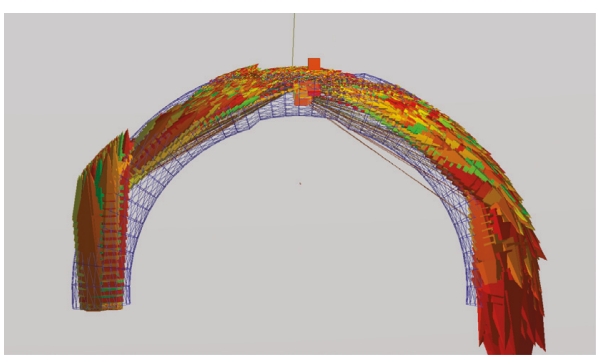

(f)

Figure 11: Conceptual example of ray propagation in a virtual half-cone test (ray vector sizes are not to scale). (a) Frame 0. (b) Frame 5k. (c) Frame 10k. (d) Frame 15k. (e) Frame 20k. (f) Accumulated view.

\section{Experimental}

3.1. POF Specimen. Commercially available PMMA-based step-index POF (Toray, Raytela ${ }^{\circledR}$ ) was chosen for experiment
(Tables 1 and 2). Fiber diameters were chosen considering the efficiency of weaving process afterwards. Light intensity was measured before and after cladding removal process. 


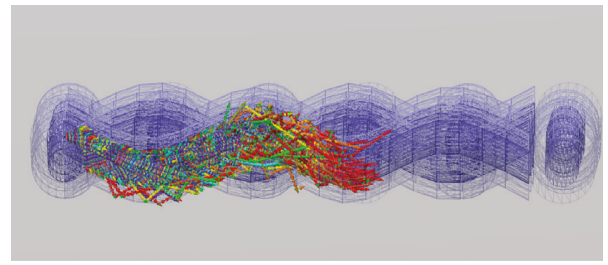

FIGURE 12: Example of ray propagation in a virtual POF-inserted plain weave fabric.

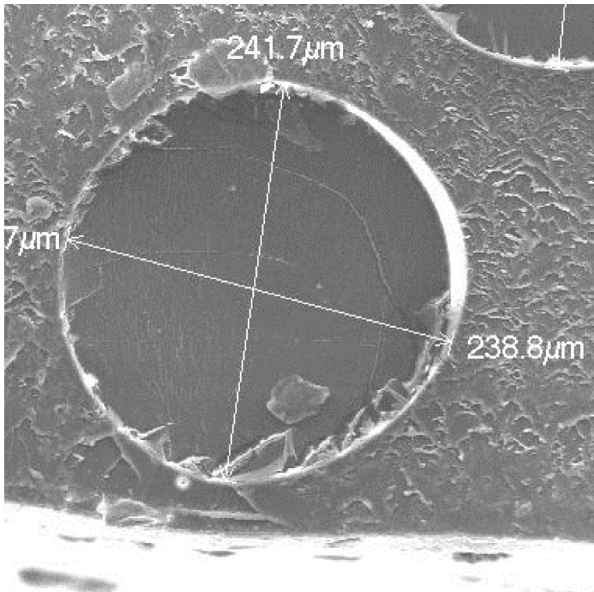

(a)

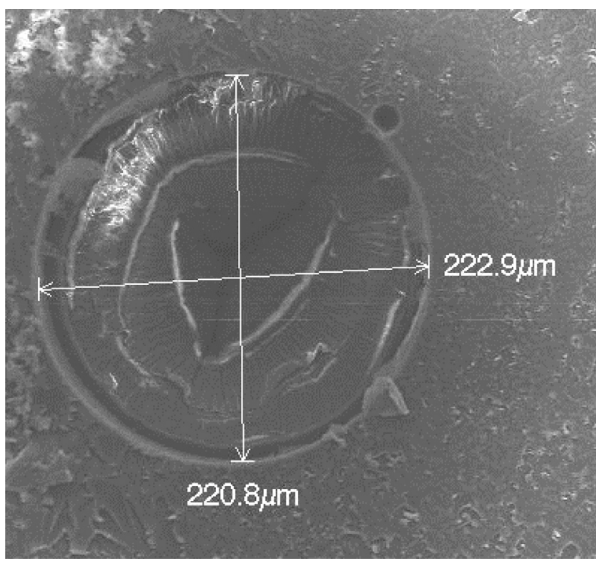

(c)

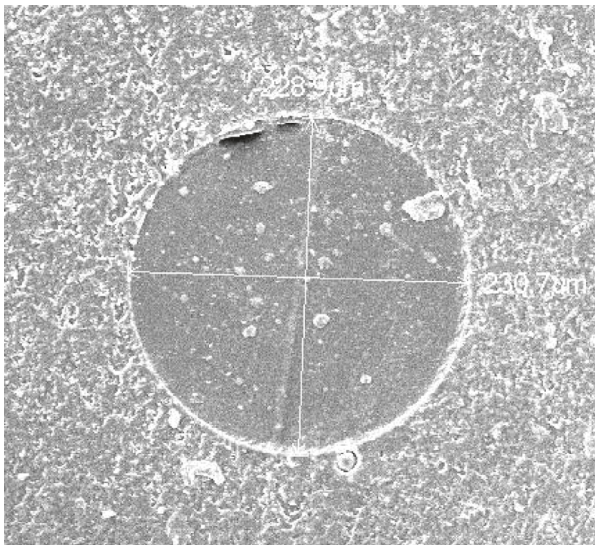

(b)

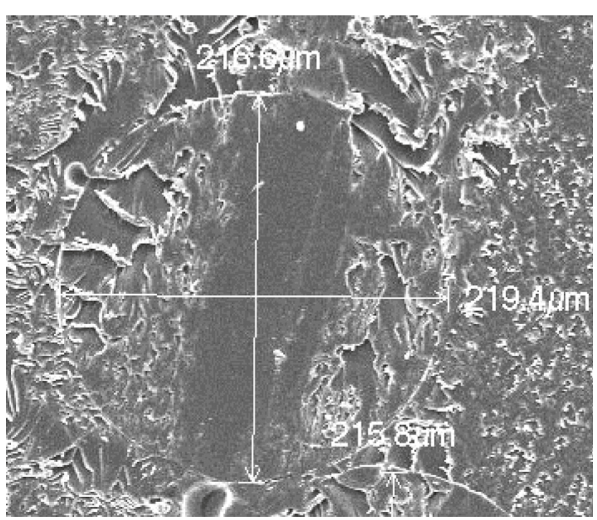

(d)

FIgure 13: Chemical clad removal using DMF with different immersion times. (a) 30 minutes. (b) 1 hour. (c) 2 hours. (d) 3 hours.

3.2. Cladding Removal. To find optimal peeling off condition, both chemical and mechanical methods were applied. For chemical approach, dimethyl ketone (DMK or acetone; from Daejung chemical corp.) and dimethyl formamide (DMF; Daejung chemical corp.) were prepared in 100\% solution. $2 \mathrm{~cm}$ length of POFs were immersed in the solution for $0.5 / 1 / 2 / 3$ hours and then water-washed. For mechanical cladding removal treatment, sandpaper (grit size P80; ISO/FEPA) was used.

To verify the cladding-removal effect, fibers were impregnated in epoxy resin, and then their cross-sections were observed using cryo-ultramicrotomer (RMC/PTPC\&CRX) and field emission scanning electron microscope (JSM-6500F, JEOL). Conventional refractive index profiler (IFA-100;
Interfiber Analysis, LLC) was also tested, but the device did not operate for fibers of irregular diameter of ours.

3.3. Light Intensity Measurement. Red light LED (627 nm; Ocean Optics, Inc.) was used for light source, considering the fact that our POF specimen shows lowest attenuation under $650 \mathrm{~nm}$. Two sets of USB-type flame spectrometer (FLAME-S-VIS-NIR, Ocean Optics corp.) were prepared to measure both the side illumination and end-tip illumination. POF, the light source, and the spectrometers were interconnected using bare fiber adapter (BFA-KIT; Ocean Optics, Inc.) to minimize connection loss. Note that the intensities in the following graphs would be shown in relative 


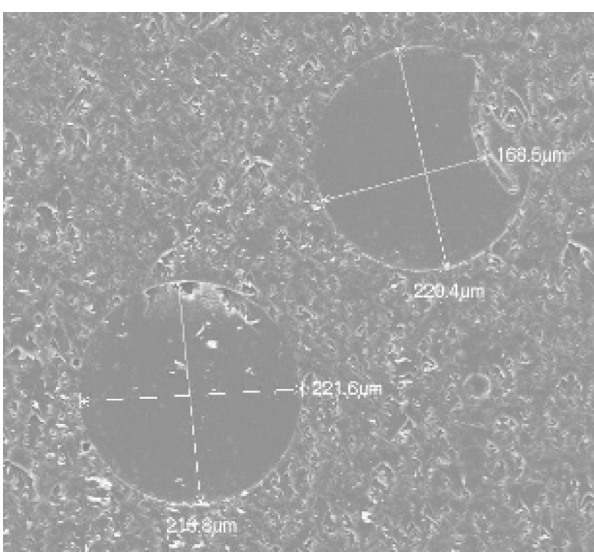

(a)

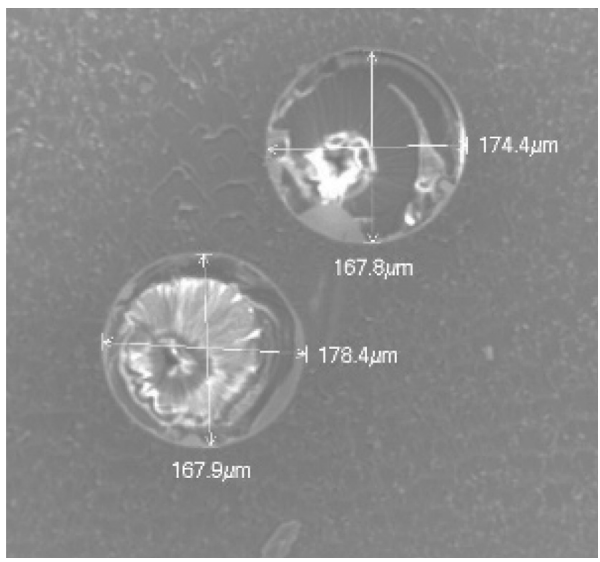

(c)

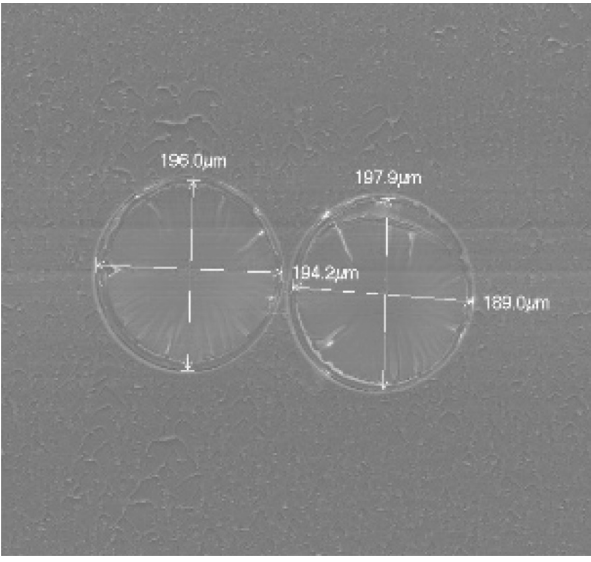

(b)

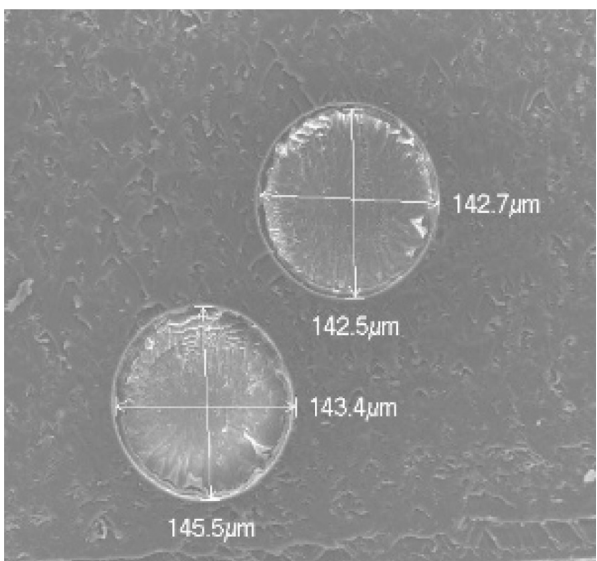

(d)

Figure 14: Chemical clad removal using acetone with different immersion times. (a) 30 minutes. (b) 1 hour. (c) 2 hours. (d) 3 hours.

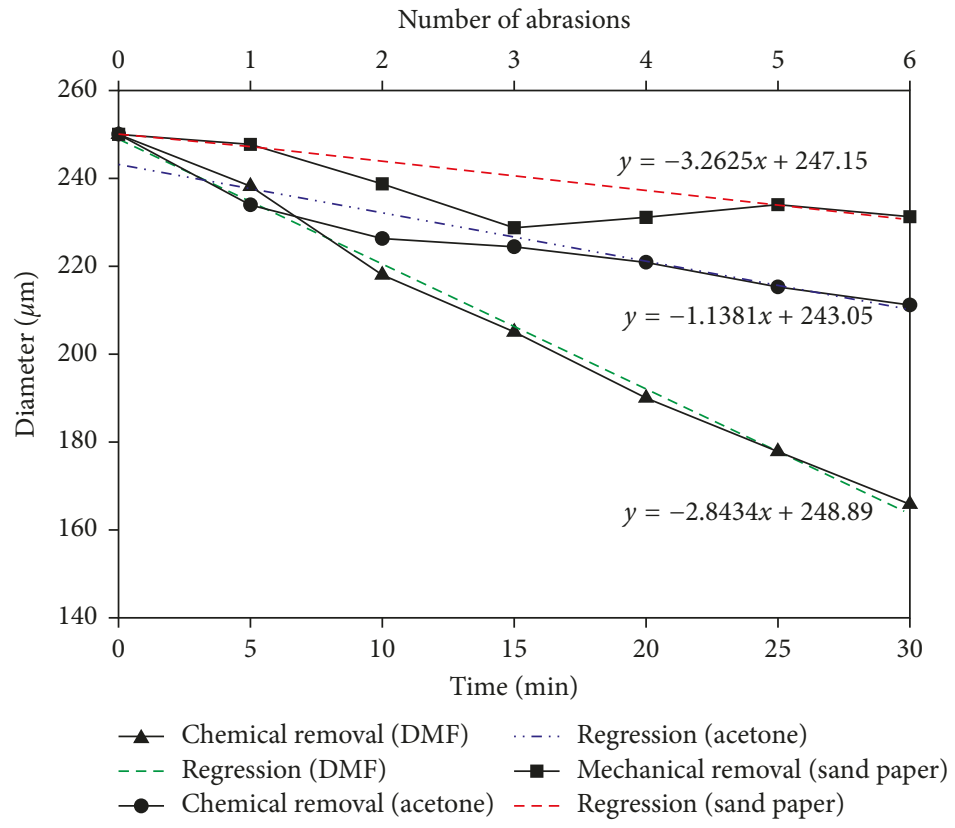

FIGURE 15: Relationship between acetone immersion time and clad removal effect (for PGR-FB250). 
normalized value, because the light strength could only be controlled manually.

3.4. Half-Cone Jig Test. To measure light delivery under exact curvature condition, a half-cone-shaped jig was designed and manufactured via 3D CAD tool $\left(123 \mathrm{D}^{\circledR}\right.$, Autodesk, Inc.; Figure 2(a)) and 3D printer (Cube Trio Pro ${ }^{\circledR}$, 3DSystemsn Inc.; Figure 2(b)). The cone height and bottom radius were designed as $200 \mathrm{~mm}$ and $125 \mathrm{~mm}$, respectively, but manufactured as $198 \mathrm{~mm}$ and $124 \mathrm{~mm}$ due to 3D printer filament's thermal shrinkage. Side-illumination, which came from the cladding-removed region, and end-tip illumination, which came from the fiber end, were simultaneously measured using the same light source and two spectrometers (Figure 3). The top surface of the exposed cladding-removed region was covered by additional 3D-printed cover, which was developed in our previous work [32].

3.5. POF-Textile Weaving. A small hand-loom (Loomini ${ }^{\circledR}$; Luziuum corp.) of $22 \mathrm{~cm} \times 32.5 \mathrm{~cm}$ size was used to make a plain weave fabric in which the POF should be laid. Plain weave means a fabric structure where warp and weft yarns are crossed one by one iteratively like checkerboard [33]. POF and wool/nylon combined yarn (70\%:30\%; diameter $3 \mathrm{~mm}$ ) were used as warp thread, while cotton/acrylic combined yarn (60\%:40\%; diameter $2 \mathrm{~mm}$ ) was used as weft thread. Figure 4 shows the plain weave textile with three kinds of POFs (PGR-FB250, PGR-FB750, and PGR-FB1000) inserted.

\section{Modeling}

4.1. Assumptions. As our concern is only to find the quantity of light delivered through POF in the fabric-thicknessdirection, the following assumptions were used for the simplicity's sake:

(i) Ray is considered as a kind of vector. It behaves like a particle in marching or total internal reflection, and it changes its course in refraction.

(ii) Each layer of POF is homogeneous material. Raymolecule interaction like Rayleigh scattering is not considered.

(iii) Rays does not intervene with each other. Harmonic mixing like four-wave mixing does not occur.

(iv) The incident light is dissipated as either side illumination or end-tip illumination. Any other geometric loss is ignored.

(v) In simulation, POF's one end is positioned at origin and extends to $+x$ axis direction. Rays start from the first center point of POF.

4.2. Algorithm Procedure. The simulation proceeds in the following order:

(i) (Step \#0) preparation step: ray vector $x_{\omega, \tau}$ with wavelength $\omega$ at time $\tau$ is generated. The number of
TABLE 4: POF diameters after clad removal (unit: $\mu \mathrm{m}$ ).

\begin{tabular}{lcccc}
\hline \multirow{2}{*}{ Removal method } & \multicolumn{4}{c}{$\begin{array}{c}\text { Chemical treatment time (\# of } \\
\text { mechanical abrasion) }\end{array}$} \\
& $0.5 \mathrm{hr}(1)$ & $1 \mathrm{hr} \mathrm{(2)}$ & $2 \mathrm{hr} \mathrm{(4)}$ & $3 \mathrm{hr}(6)$ \\
\hline Chemical (acetone) & 216 & 187 & 172 & 143 \\
Chemical (DMK) & 245 & 235 & 224 & 219 \\
Mechanical (sandpaper) & 247 & 244 & 237 & 230 \\
\hline
\end{tabular}

$x_{\omega, \tau}$ follows Gaussian distribution. Orientation of $x_{\omega, \tau}$ are given some deviation, whose maximal value lies inside the acceptance angle of the POF. POF mesh model with number of cylinder center $N_{\mathrm{cs}}$ is prepared. Core and clad cylinders are assigned to each center.

(ii) (Step \#1) marching step: for each ray vector $x_{\omega, \tau}$, update its position by time step $\Delta t$ and get new vector $x_{\omega, \tau+1}$. Increase number of iteration by 1 .

(iii) (Step \#2) collision detection step: to check collisions between ray and clad-core interface, search the nearest center point $c_{i}$ from $x_{\omega, \tau+1}$. Check the collision in cylinder $\left[\mathbf{c}_{i} \sim \mathbf{c}_{i+1}\right]$.

(iv) (Step \#3) update step: Accept $x_{\omega, \tau+1}$ if no collision occurred. Otherwise, modify $x_{\omega, \tau+1}$ (see Section 4.6). Display the vectors and prepare the wavelength distribution chart. If the number of iteration exceeds some criteria, stop. Otherwise, go back to step \#1.

4.3. Fiber Model. Hollow-cylinder-shaped fiber model was proposed to represent POF with arbitrary curvature and thickness. Each fiber was considered to be a collection of cylinder center point $\mathbf{c}_{i}$ 's (Figure 5(a)). Each center point pair, that is, $\mathbf{c}_{i}$ and $\mathbf{c}_{i+1}$, comprised a repeat unit. A hollow-shaped cylinder is assigned one by one for each layer of POF, that is, core and cladding, with different radii (Figure $5(\mathrm{~b})$ ). These radii, that is, $R_{\text {core }}$ and $R_{\text {clad, }}$, would be used for later $3 \mathrm{D}$ rendering and ray collision detection. Shape or curvature of the fiber could be controlled by moving control points $\mathbf{c}_{i}$. Figure 5(c) shows simulation model for half-cone test. Each center point was adjusted in its position using cantilever beam analogy. Equations (1) and (2) show conditions needed in finding the deflected new data positions $\mathbf{c}_{i}{ }^{\prime}$ for a given $R_{c}$ value.

$$
\begin{gathered}
\left\|\mathbf{c}_{i}^{\prime}-\mathbf{O}_{c}\right\|=R_{c}, \\
\sum_{i=0}^{N_{\mathrm{cs}}-2}\left\|\mathbf{c}_{i}^{\prime}-\mathbf{c}_{i+1}^{\prime}\right\|=\sum_{i=0}^{N_{\mathrm{cs}}-2}\left\|\mathbf{c}_{i}-\mathbf{c}_{i+1}\right\| .
\end{gathered}
$$

Figure 6 shows the resultant artificial POFs with varying curvature of radii values using the hollow-cylinder structure.

4.4. Cladding-Removal Simulation. Cladding-removal was simulated by adjusting the radii of cylinders in Figure 5(b). When cladding-removal mode was turned on, the user-selected 


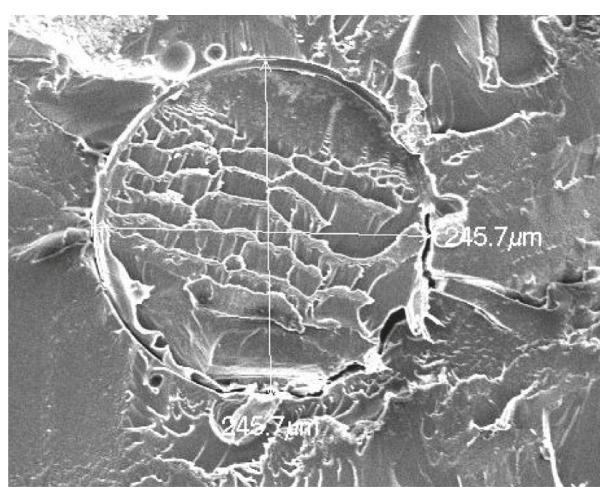

(a)

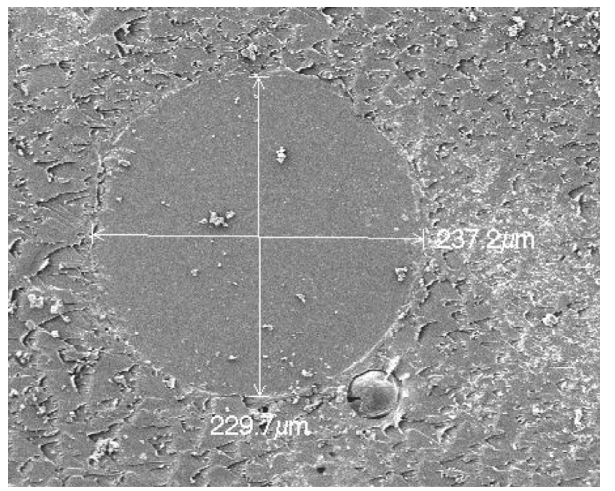

(c)

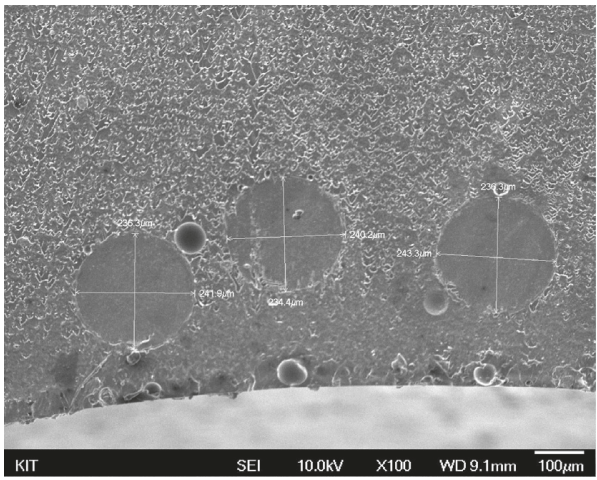

(b)

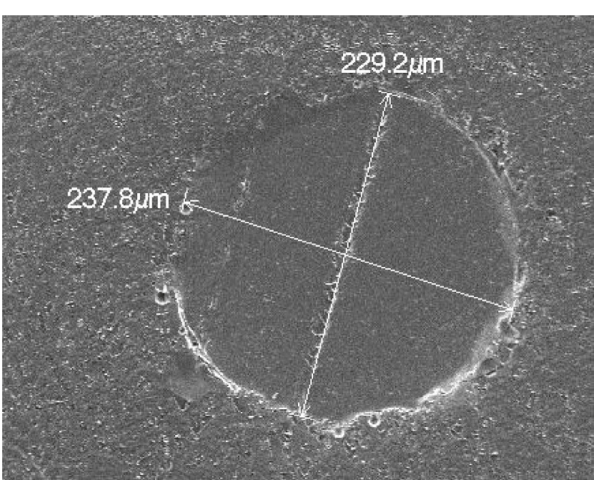

(d)

FIgURE 16: Mechanical clad removal using sandpaper with different abrasion numbers. (a) 1 time. (b) 2 times. (c) 4 times. (d) 6 times.

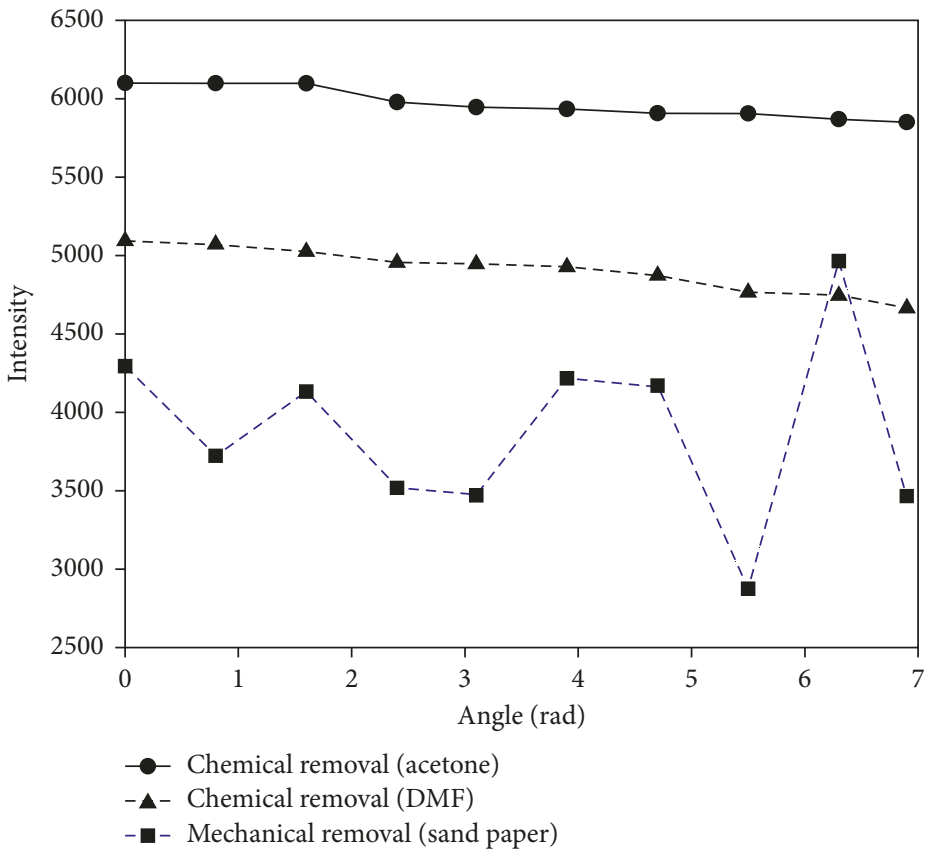

FIGURE 17: Radial distribution of maximum side-illumination of PGR-FB250 specimen after chemical and mechanical treatment. 


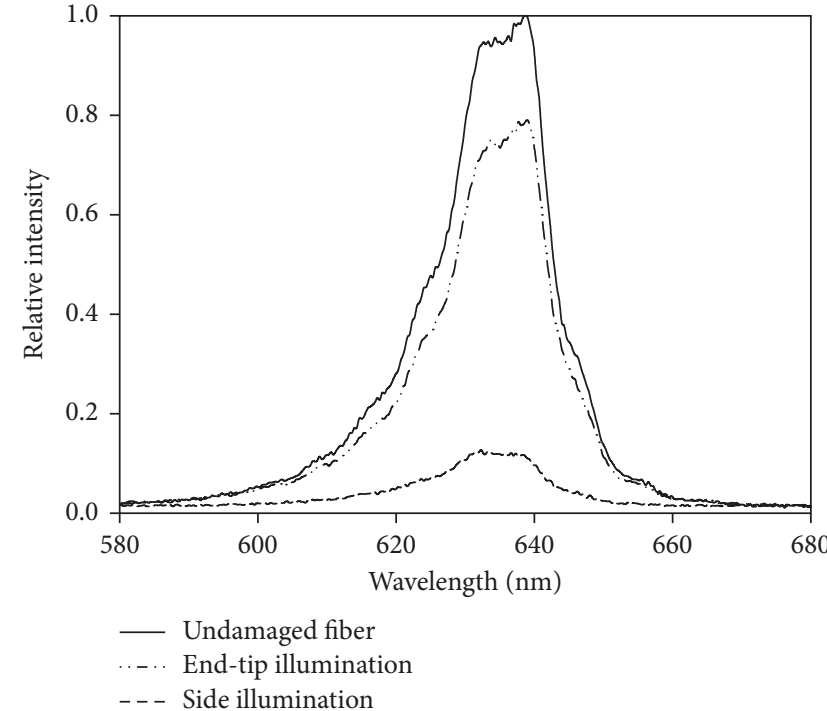

(a)

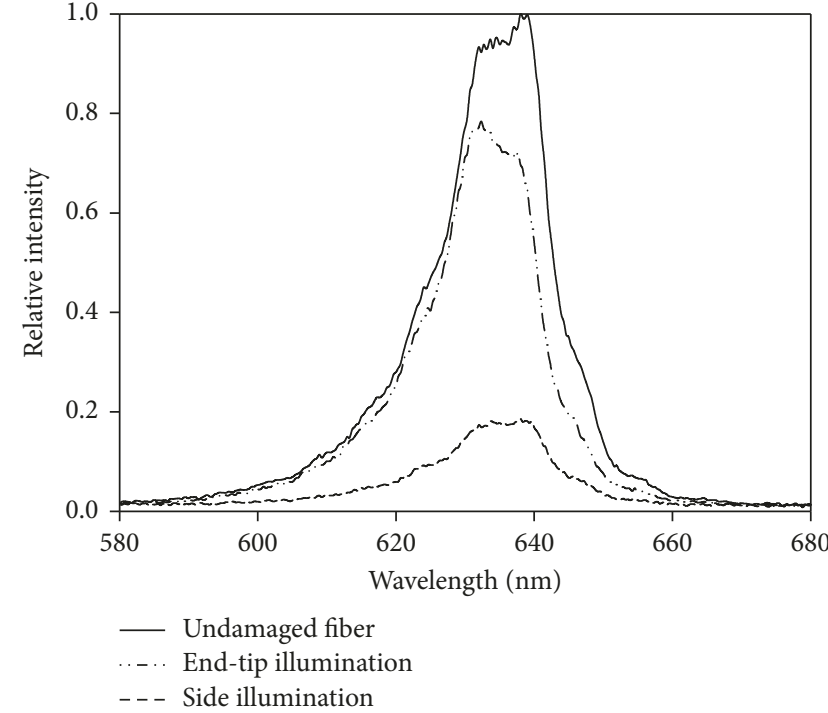

(b)

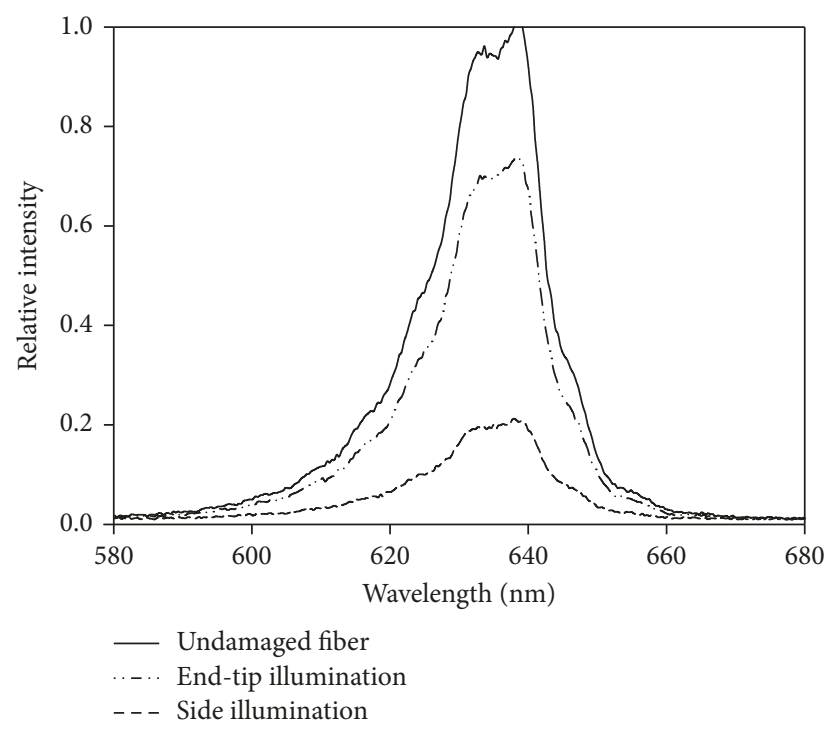

(c)

FIgURE 18: Comparison of side illumination and end-tip illumination for the three POF specimens. (a) PGR-FB250. (b) PGR-FB750. (c) PGR-FB1000,

cylinder segment was heighted (Figure 7(a)). If a user inputted the new diameter of core and cladding, the resultant fiber was updated and displayed (Figure 7(b)). Repeating this procedure, user could remove POF cladding as much as needed (Figures $7(\mathrm{c})$ and $7(\mathrm{~d})$ ).

4.5. Window-Based Simulation Software. The proposed simulation technique was implemented with $\mathrm{C}++$ language $(\mathrm{C}++$ Builder XE5; Embarcadero Technologies, Inc.) under MS Window 764 bit O/S. OpenGL 2.0 shading language was used for the 3D display of objects. Micrometer was used as default unit for fiber dimension and ray wavelength representation. Figure 8 shows the screenshot of the simulation software running.
4.6. Ray-to-Interface Collision Detection. The ray vectors had been marched step by step, until they met core-cladding or cladding-air interface. Their final positions were modified based on the Snell's law [21]. Collision point $\mathbf{p}_{c}$ can be found from a simple bilinear interpolation parameter $t_{c}$,

$$
\mathbf{p}_{c}=\left(1-t_{c}\right) \cdot \mathbf{p}_{0}+t_{c} \cdot \mathbf{p}_{1} \text {, where } t_{c}=\frac{\left(R_{\text {core }}-d_{0}\right)}{\left(d_{1}-d_{0}\right)},
$$

and $\mathbf{p}_{1}$ denotes a vector end point when $\mathbf{n}_{\text {core }}=\mathbf{n}_{\text {clad }}$. Vector after refraction $\mathbf{v}_{1 c, \text { rfr }}$ can be known simply by

$$
\vec{v}_{1 \mathrm{c}, \mathrm{rfr}}=\mathbf{p}_{1, \mathrm{rfr}}-\mathbf{p}_{c} \text {. }
$$

And then vector end point after total inflection $\mathbf{p}_{1, \text { tif }}$ becomes 


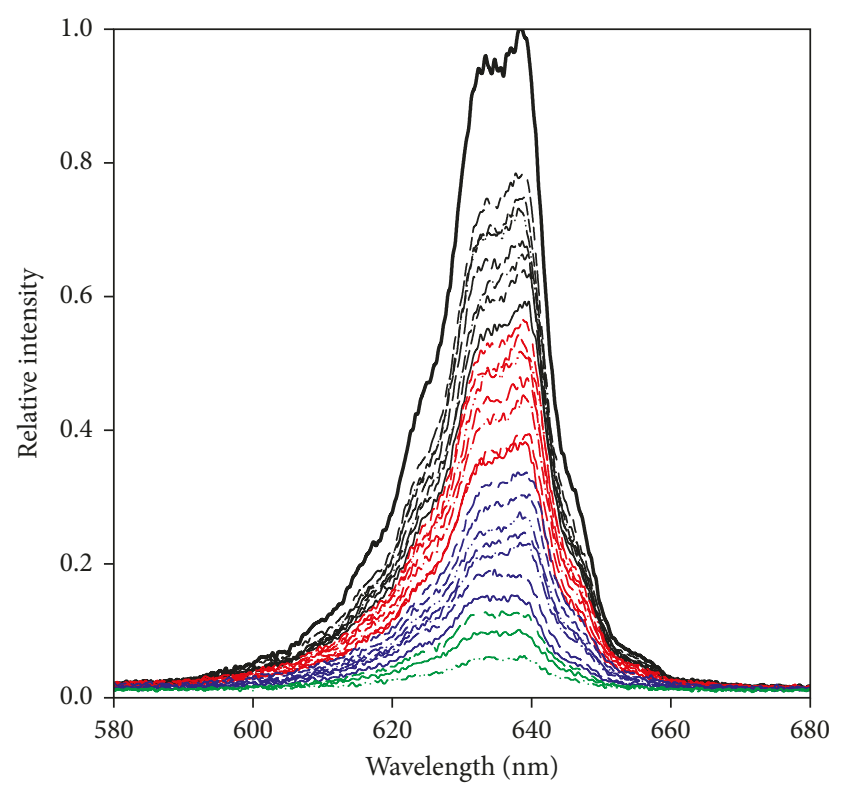

$R c(\mathrm{~mm})$

\begin{tabular}{|c|c|c|}
\hline —— (Undamaged fiber) & --15 & -32.0 \\
\hline-0 & - 16. & - 33.8 \\
\hline--1.9 & -18. & - 35.7 \\
\hline - 3.8 & -. 20 & -37.6 \\
\hline-5.6 & -.22 & --39.5 \\
\hline -.. 7.5 & -24 & --41.4 \\
\hline-9.4 & --26 & —. 43.2 \\
\hline - 11.3 & --28 & \\
\hline 13.2 & 30. & \\
\hline
\end{tabular}

FIGURE 19: Delivered light intensity at the PGR-FB250 fiber end tip.

$$
\begin{aligned}
\mathbf{p}_{1, \mathrm{tif}} & =\mathbf{p}_{c}+\overrightarrow{\mathbf{v}}_{1 \mathrm{c}, \mathrm{tif}} \\
& =\mathbf{p}_{c}+\left(\mathbf{I}_{33}-\overrightarrow{\mathbf{n}}_{c} \cdot \overrightarrow{\mathbf{n}}_{c}^{T}\right) \cdot \overrightarrow{\mathbf{v}}_{1 \mathrm{c}, \mathrm{ffr}}, \text { where } \overrightarrow{\mathbf{n}}_{c}=\frac{\left(\mathbf{p}_{c}-\mathbf{r}_{c}\right)}{\left\|\mathbf{p}_{c}-\mathbf{r}_{c}\right\|}
\end{aligned}
$$

Figure 9 shows the scheme of ray-to-interface collision detection. The detailed description on the parameters is listed in Table 3.

The ray vector was assigned a status flag "INITIAL" when they started to march, "STOPPED" when they go out of the fiber, and "REFLECTED" and "REFRACTED" when they make reflection or refraction, respectively. Each number of flags was counted to make a final artificial photometer graph (Figure 10).

Figures 11 and 12 show an example of ray marching simulation for a virtual half-cone jig test (Figure 11) and a fiber within plain weave structure (Figure 12). The plain weave's crimp curve was generated by applying sinusoidal function to the center point point $\mathbf{c}_{i}$.

\section{Results and Discussion}

5.1. Cladding Removal. Several famous solvents, such as benzene, cyclohexane, sodium hydroxide powder, ethanol, hydrogen chloride, were tried as cladding removal agent.
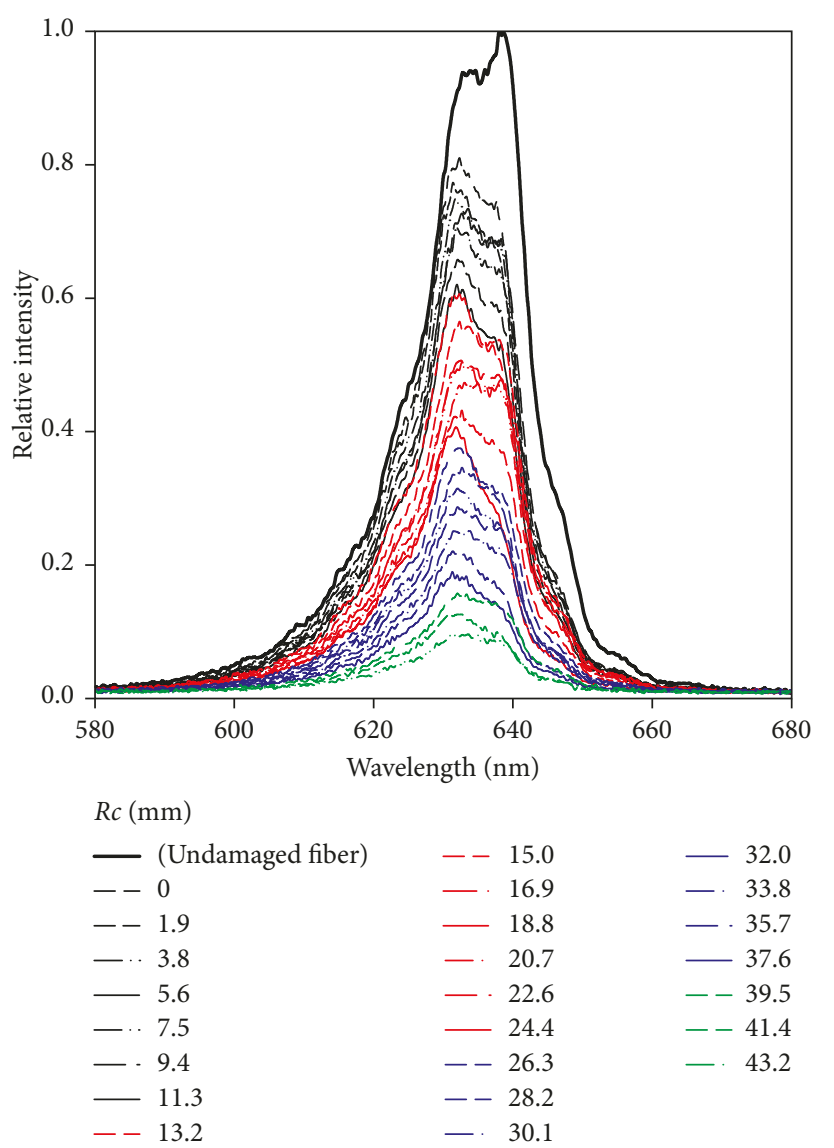

FIGURE 20: Delivered light intensity at the PGR-FB750 fiber end tip.

But they were not suitable because some did not erode the cladding at all, or others reacted with PMMA, leaving very dirty surface. Only DMF and acetone showed satisfactory result.

Figures 13 and 14 show the cladding removal results using chemical (DMF/acetone) agent for PGR-FB250 specimen. Diameters measured after treatment are displayed in Figure 15 and Table 4. DMF was the most advantageous in the removing speed (Figure 15), and also the cross-sectional boundary after treatment was also very clean throughout the various immersion times (Figure 13). The clean boundary means that dissipated light can have equal radial distribution at side-illumination. However, fast removal time can sometimes be a disadvantage in process control aspect. Our specimens have so small cladding thickness $(10 \mu \mathrm{m}$ in the case of PGR-FB250) that excessive immersion with DMF can unnecessarily damage the core layer. Moreover, DMF is toxic (health danger index 2; NFPA 704) [34, 35] and volatile organic agent, which is not so environment friendly. So acetone was chosen alternatively for our cladding removal agent. It shows about half speed of DMF, and the plotted point in the graph deviates more from the regression line compared with that of DMF. However, it is less toxic (health danger index 1; NFPA 704), and its lower abrasion speed (Figure 15) can be more advantageous in controlling the operation speed.

Also, mechanical peeling off agent was tested. The diameter decreased easily with a few number of abrasions only 


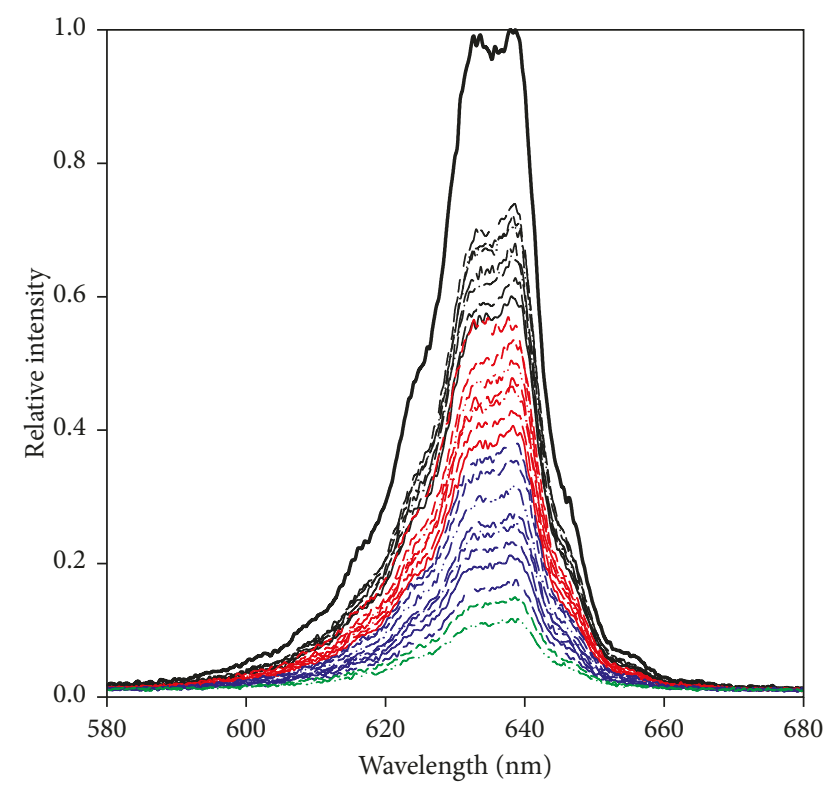

$R c(\mathrm{~mm})$

\begin{tabular}{|c|c|c|c|}
\hline- & (Undamaged fiber) & -- & 15 \\
\hline-- & 0 & - & \\
\hline-- & 1.9 & $\longrightarrow$ & \\
\hline - & 3.8 & - & \\
\hline 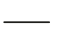 & 5.6 & - & \\
\hline$-\cdots$ & 7.5 & $\longrightarrow$ & \\
\hline- & 9.4 & -- & \\
\hline - & 11.3 & -- & \\
\hline-- & 13.2 & - & \\
\hline
\end{tabular}

FIgUre 21: Delivered light intensity at the PGR-FB1000 fiber end tip.

(Figure 15). The treated boundary was clean (Figure 16), but the fiber dimension was not regular with respect to the radial direction (especially Figure 16(d)). Figure 17 shows the radial distribution of side-illumination for both acetone and sandpaper treatment, respectively. Sandpaper-based method shows less evenness in the graph. Generally, textiles have relatively small thickness compared to area, and the sideilluminated light is expected to be dissipated to the out-ofplane direction. In this case, mechanical abrasion can control the direction of the treated surface, and this radial irregularity can be helpful. However, acetone-based chemical treatment was chosen to guarantee the evenness of abrasion quality in this paper.

5.2. Comparison of Side and End-Tip Measurement. The purpose of half-cone test in Figure 3 was to find proper illumination spot for our specially designed POF. Conventional POF is given light from one end and measured the intensity at the other. Our fiber had another exit, which was the cladding-removed region, and the accuracy of sideillumination measurement method was questioned. So we measured both side illumination and end-tip illumination under the same light source. Figure 18 shows the results for the three kinds of POF specimens, respectively. Theoretically, areal sum of side illumination and end-tip illumination

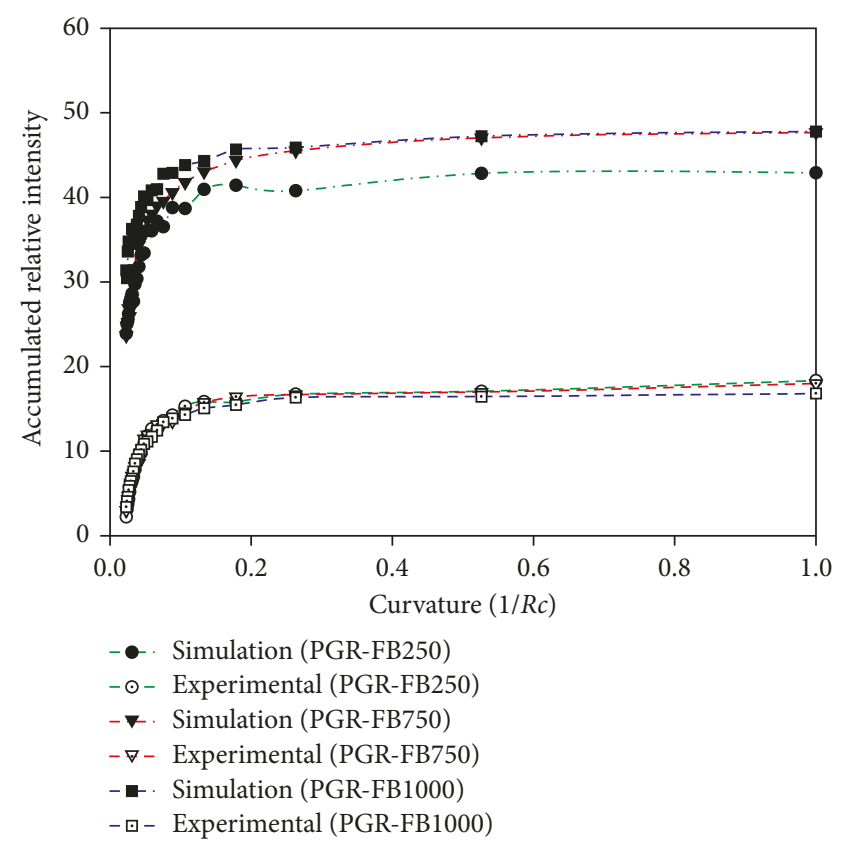

FIgURE 22: Comparison of simulation and experiment for the half cone jig test.

should be equal to that of undamaged fiber. But Figure 18 showed that there was $2 \sim 3 \%$ error. This may be due to the connection error between a fiber and the cover structure. The error norm was constant level through the tests, but not negligibly small. So it was natural to choose end-tip measurement type in this paper, where the number of cladremoved region is only one for each fiber. However, if the number of clad-removed sites is multiple, it is worthy to consider side-measurement type instead.

5.3. Effect of Curvature to Illumination. Figures 19-21 show the experimental results for half-cone jig tests. The radius of curvature ranged from 0 to $43.2 \mathrm{~mm}$. Firstly, Figure 19 is the end-tip illumination experiment result for PGR-FB250 POF after 3-minute acetone immersion treatment. Note that curve from the undamaged fiber of Figure 18(a) was added to the top most position (thick solid line) as reference. The increase of radius of curvature showed linear relationship with the decrease of end-tip illumination. It seems that global bending within the fiber increased the incidence angle $\theta_{0}$ of (1), leading to more number of reflected light vectors outside the fiber core.

Figure 20 is the result at the same condition for PGRFB750 fiber. The linear tendency is the same, while wavelength above $635 \mathrm{~nm}$ shows more loss. The phenomenon becomes more vivid in Figure 21, which is for PGR-FB1000 fiber. Wavelength under $635 \mathrm{~nm}$ was also decreased in this case. The major difference between PGR-FB2500, PGRFB750, and PGR-FB1000 was the radii. The thicker fiber would be given more bending moment under same radius of moment.

The experimental data were compared with those from simulation. Figure 22 illustrates the integral sum of the graph 
TABLE 5: Simulation speed for virtual half-cone test (POF length $=5 \mathrm{~mm}$ ).

\begin{tabular}{lcccc}
\hline Number of rays & $N_{\mathrm{cs}}$ & Curvature $\left(1 / R_{c}\right)$ & Number of time steps & Simulation time (min : sec.msec) \\
\hline 100 & 10 & 0 & 10,000 & $0: 07.767$ \\
100 & 20 & 0 & 10,000 & $0: 10.270$ \\
100 & 40 & 0 & 10,000 & $0: 11.112$ \\
1009 & 40 & 0 & 10,000 & $1: 25.208$ \\
1009 & 40 & 10 & 10,000 & $1: 59.851$ \\
1009 & 40 & 40 & 10,000 & $1: 57: 344$ \\
1009 & 40 & 80 & 10,000 & $1: 59: 354$ \\
2007 & 40 & 0 & 10,000 & $3: 53.325$ \\
4015 & 40 & 0 & 10,000 & $7: 42: 042$ \\
8005 & 40 & 0 & 10,000 & $15: 19.802$ \\
\hline
\end{tabular}

$N_{c s}=$ number of cylinder centers.

area of Figures 19-21, with simulation results added. The simulation showed highly linear relationship between radius of curvature and end-tip illumination. There was slight difference in the inclination between the simulation and the experiment. The error source could be that radius of curvature was not properly controlled in the simulation because our model uses discrete series of cylinders instead of continuous ones.

Table 5 lists the simulation time for virtual half-cone test of Figure 11. The time was linearly dependent on the number of rays and cylinder center points. Existence of POF curvature delayed calculation, but the degree of curvature did not show linear relationship with the calculation time. The reason is thought to be that collision detection is checked for every ray vector in each frame. An efficient skipping algorithm such as temporal coherence would accelerate the calculation. This means that our ray-tracing-based approach is a suitable method for textile-based POF ray delivery modeling quantitatively and qualitatively.

5.4. Illumination within Weave Structure. Finally, the cladremoved fibers of three different radii were impregnated within a plain-weave textile structure after 3-minute acetone treatment. Plain weave structure was chosen because fibers were given more crimp deformation than in twill or satin. Figure 23 shows the result. It reveals that the thicker fiber showed more loss in the end-tip illumination, which means more lights were dissipated in the clad-removed region. Bigger radius means that the more possibility lies that ray vector can travel through the fiber with larger incident angle out of total internal reflection criteria. The simulation showed also similar relationship. It is also our further work to test other weave types, that is, satin, twill, or arbitrary structure, for side illumination effect of clad-removed POF.

\section{Conclusions}

Wearable computer needs two necessary components: media that contains information and material that transfer the media. In this paper, light was selected as an alternative media for information delivery, instead of electricity. And as material candidate, POF was chosen for our research

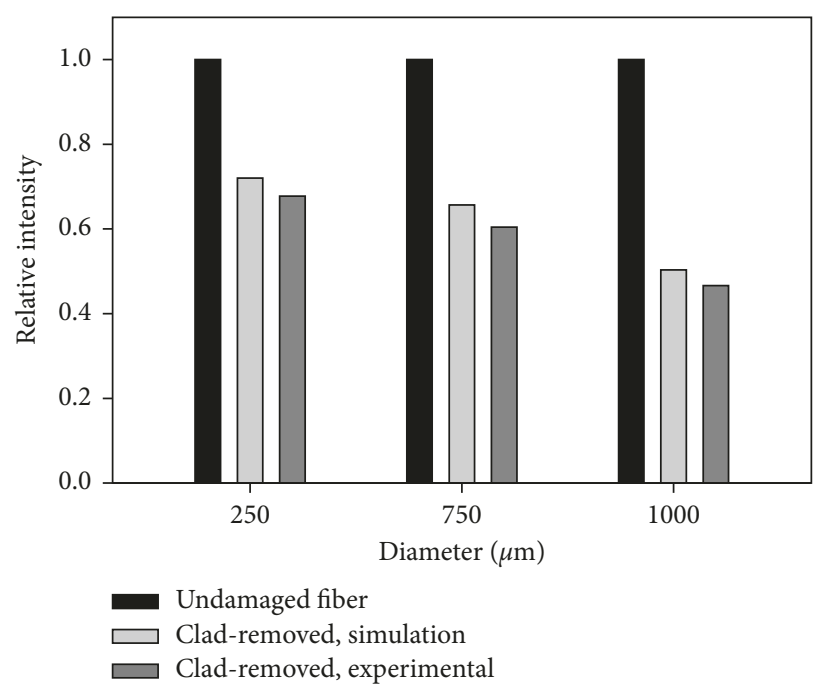

FIGURE 23: End-tip illumination of POF in plain weave fabric.

because it was the most flexible enough to withstand severe curvature of textile. To find the optimal condition for curved POF light delivery, both experimental and theoretical approaches were taken.

For experiment, the fiber cladding was partially removed by chemical or mechanical treatment for better fiber radial direction dissipation or, namely, side illumination. DMF showed the better peeling effect, but acetone was chosen because of DMF's toxicity. Optimal clad-removing condition was found that about 2-minute immersion in acetone was enough to remove cladding layer of $250 \mu \mathrm{m}$ diameter POF. Commercially available POF of three different sizes was used as specimen, and a specially designed half-coneshaped jig was used for reliable curvature condition. The side illumination could be used to measure radial-direction light dissipation directly, but it showed about $2 \%$ error. Alternatively, end-tip illumination was measured throughout the paper, and its amount was in linear relationship with the radius of curvature. A simple plain weave textile structure with POF impregnated was generated with a hand-loom, and it showed that thicker fiber was given more bending rigidity, which leaded to more side illumination of $\mathrm{POF}$. 
Also, the proposed method was modeled theoretically. Window-based ray-tracing software was developed to deal with complex textile weave structure geometry. Light ray was considered to be a series of discrete vectors, and the collision between ray vector and material interface was calculated. The half-cone test and weave structure were also simulated in the software. There was a little error between simulation and experimental values because material dispersion was not considered in the simulation. However, the simulated result showed the same curvature-illumination linear relationship like the experimental one. It is our further work to extend the modeling to more complex weave structures, such as twill, satin, and arbitrary Jacquard weaves.

\section{Conflicts of Interest}

The authors declare that there are no conflicts of interest regarding the publication of this paper.

\section{Acknowledgments}

This work was supported by the National Research Foundation of Korea (NRF) grant funded by the Korea government (Ministry of Science, ICT and Future Planning) (no. NRF-2014R1A1A1002463). Also, this study was carried out with the support of the Global Expertise Development Project (10048412) of the Ministry of Trade, Industry, and Energy in 2016.

\section{References}

[1] Y. Luo, B. Yan, M. Li et al., "Analysis of multimode POF gratings in stress and strain sensing applications," Optical Fiber Technology, vol. 17, no. 3, pp. 201-209, 2011.

[2] B. W. An, J. H. Shin, S.-Y. Kim et al., "Smart sensor systems for wearable electronic devices," Polymers, vol. 9, no. 8, p. 303, 2017.

[3] X. Bao, D. J. Webb, and D. A. Jackson, "32-km distributed temperature sensor based on Brillouin loss in an optical fiber," Optics Letters, vol. 18, no. 18, pp. 1561-1563, 1993.

[4] C. Bariain, I. R. Matías, F. J. Arregui, and M. López-Amo, "Optical fiber humidity sensor based on a tapered fiber coated with agarose gel," Sensors and Actuators B: Chemical, vol. 69, no. 1-2, pp. 127-131, 2000.

[5] S. Baurley, "Interactive and experiential design in smart textile products and applications," Personal and Ubiquitous Computing, vol. 8, no. 3-4, pp. 274-281, 2004.

[6] L. Van Langenhove and C. Hertleer, "Smart clothing: a new life," International Journal of Clothing Science and Technology, vol. 16, no. 1, pp. 63-72, 2004.

[7] G. W. Ho, "Gas sensor with nanostructured oxide semiconductor materials," Science of Advanced Materials, vol. 3, no. 2, pp. 150-168, 2011.

[8] L. M. Castano and A. B. Flatau, "Smart fabric sensors and e-textile technologies: a review," Smart Materials and Structures, vol. 23, no. 5, p. 053001, 2014.

[9] E. Devaux, V. Koncar, B. Kim et al., "Processing and characterization of conductive yarns by coating or bulk treatment for smart textile applications," Transactions of the Institute of Measurement and Control, vol. 29, no. 3-4, pp. 355-376, 2007.

[10] A. Kaynak and R. Beltran, "Effect of synthesis parameters on the electrical conductivity of polypyrrole-coated poly (ethylene terephthalate) fabrics," Polymer International, vol. 52, no. 6, pp. 1021-1026, 2003.

[11] R. L. Hadimani, D. V. Bayramol, N. Sion et al., "Continuous production of piezoelectric PVDF fibre for e-textile applications," Smart Materials and Structures, vol. 22, no. 7, p. $075017,2013$.

[12] A. Onodera, N. Tamaki, Y. Kawamura, T. Sawada, and H. Yamashita, "Dielectric activity and ferroelectricity in piezoelectric semiconductor Li-doped $\mathrm{ZnO}$," Japanese Journal of Applied Physics, vol. 35, no. 9, p. 5160, 1996.

[13] S. Choi, S. Kwon, H. Kim et al., "Highly flexible and efficient fabric-based organic light-emitting devices for clothingshaped wearable displays," Scientific reports, vol. 7 , no. 1, p. 6424, 2017.

[14] M.-S. Lee, K. Lee, S.-Y. Kim et al., "High-performance, transparent, and stretchable electrodes using graphenemetal nanowire hybrid structures," Nano Letters, vol. 13, no. 6, pp. 2814-2821, 2013.

[15] J. Kim, M. Kim, M.-S. Lee et al., "Wearable smart sensor systems integrated on soft contact lenses for wireless ocular diagnostics," Nature Communications, vol. 8, 2017.

[16] J. Jang, B. G. Hyun, S. Ji et al., "Rapid production of large-area, transparent and stretchable electrodes using metal nanofibers as wirelessly operated wearable heaters," NPG Asia Materials, vol. 9, no. 9, p. e432, 2017.

[17] A. Jo, Y. Seo, M. Ko et al., "Textile resistance switching memory for fabric electronics," Advanced Functional Materials, vol. 27, no. 15, 2017.

[18] L. Hu, M. Pasta, F. L. Mantia et al., "Stretchable, porous, and conductive energy textiles," Nano Letters, vol. 10, no. 2, pp. 708-714, 2010.

[19] G. Keiser, Optical Fiber Communications, Wiley Online Library, New Delhi, India, 2003.

[20] Y. S. Choi and B. W. Kim, "Photocatalytic disinfection of E coli in a UV/TiO2-immobilised optical-fibre reactor," Journal of Chemical Technology and Biotechnology, vol. 75, no. 12, pp. 1145-1150, 2000.

[21] J. Hecht, Understanding Fiber Optics, Jeff Hecht, Auburndale, MA, USA, 2015.

[22] D. B. Keck, "Optical fiber waveguides," in Fundamentals of Optical Fiber Communications, M. K. Barnoski, Ed., Academic Press, New York, NY, USA, 2nd edition, 1981, https: //www.elsevier.com/books/fundamentals-of-optical-fibercommunications/barnoski/978-0-12-079151-4.

[23] T. Ishigure, E. Nihei, and Y. Koike, "Optimum refractive-index profile of the graded-index polymer optical fiber, toward gigabit data links," Applied Optics, vol. 35, no. 12, pp. 2048-2053, 1996.

[24] G. Durana, J. Zubia, J. Arrue, G. Aldabaldetreku, and J. Mateo, "Dependence of bending losses on cladding thickness in plastic optical fibers," Applied Optics, vol. 42, no. 6, pp. 997-1002, 2003.

[25] M. Lomer, J. Arrue, C. Jauregui, P. Aiestaran, J. Zubia, and J. M. López-Higuera, "Lateral polishing of bends in plastic optical fibres applied to a multipoint liquid-level measurement sensor," Sensors and Actuators A: Physical, vol. 137, no. 1, pp. 68-73, 2007.

[26] D. Barnhart, "Program announcements: optica," Mathematica Journal, vol. 5, no. 3, pp. 9-11, 1995.

[27] J. Spigulis and D. Pfafrods, "Clinical potential of the side-glowing optical fibers," in Proceedings of the SPIE-The International Society For Optical Engineering, SPIE International Society For Optical, San Diego, CA, USA, July-August 1997.

[28] J. Xu, Y. Ao, D. Fu et al., "Photocatalytic activity on $\mathrm{TiO}_{2}$-coated side-glowing optical fiber reactor under solar light," Journal 
of Photochemistry and Photobiology A: Chemistry, vol. 199, no. 2-3, pp. 165-169, 2008.

[29] R. Kashyap, Fiber Bragg Gratings, Academic Press, Cambridge, MA, USA, 2009.

[30] C.-L. Zhao, X. Yang, M. S. Demokan, and W. Jin, "Simultaneous temperature and refractive index measurements using a 3 slanted multimode fiber Bragg grating," Journal of Lightwave Technology, vol. 24, no. 2, p. 879, 2006.

[31] C. Jáuregui, A. Quintela, and J. M. López-Higuera, "Interrogation unit for fiber Bragg grating sensors that uses a slanted fiber grating," Optics Letters, vol. 29, no. 7, pp. 676-678, 2004.

[32] S. H. Moon and I. Sul, "Generation of light emission fabric using pmma/ps based clad-stripped plastic optical fiber," International Journal of GEOMATE, vol. 13, no. 36, pp. 122125, 2017.

[33] S. Kawabata, M. Niwa, and H. Kawai, "3-The finitedeformation theory of plain-weave fabrics part I: the biaxial-deformation theory," Journal of the Textile Institute, vol. 64 , no. 1, pp. 21-46, 1973.

[34] D. J. Leggett, "Rapid identification of reactivity hazards in a multiuse facility," Process Safety Progress, vol. 25, no. 2, pp. 108-115, 2006.

[35] A. Gescher, "Metabolism of N, N-dimethylformamide: key to the understanding of its toxicity," Chemical Research in Toxicology, vol. 6, no. 3, pp. 245-251, 1993. 


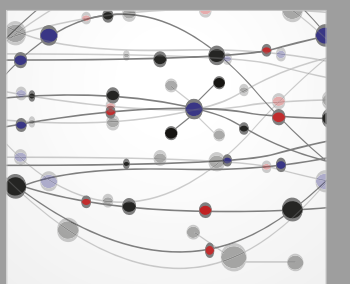

The Scientific World Journal
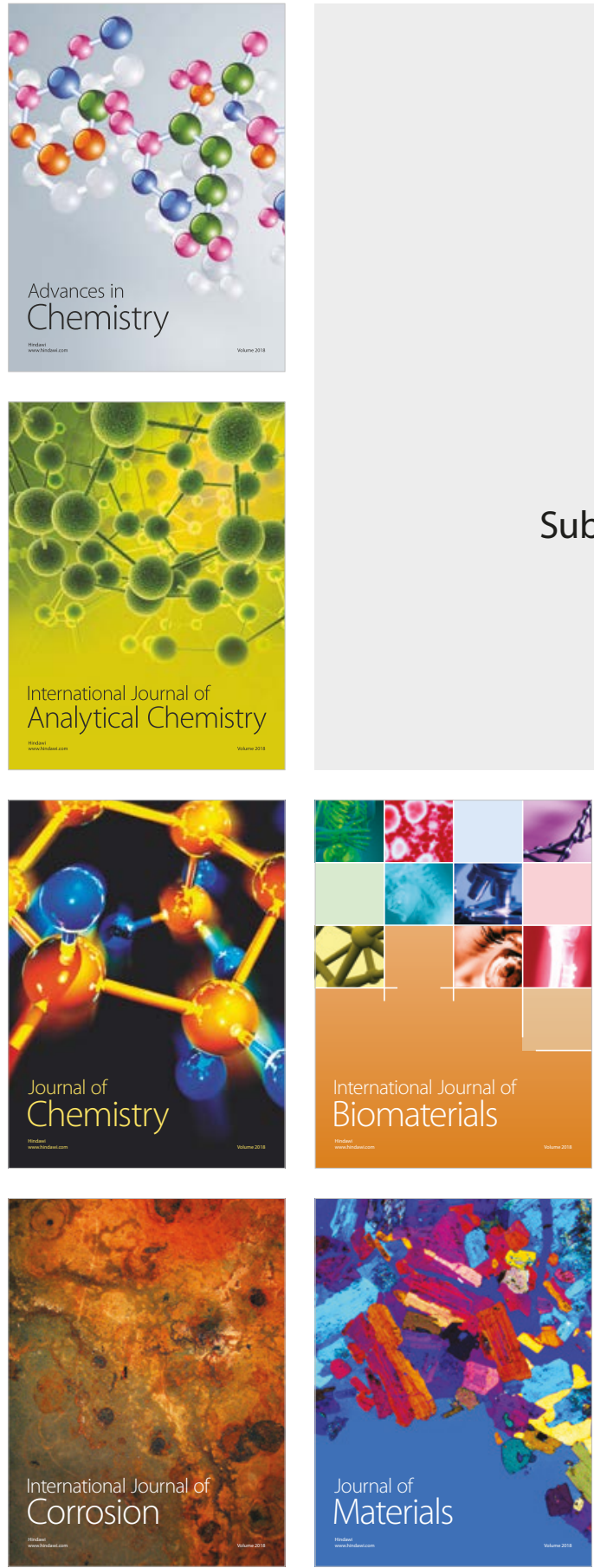

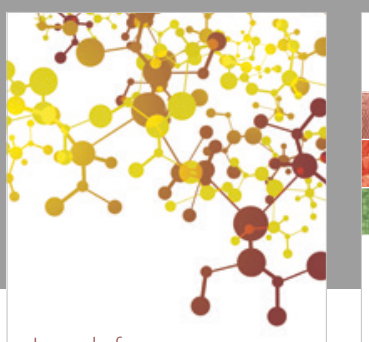

Journal of

Applied Chemistry
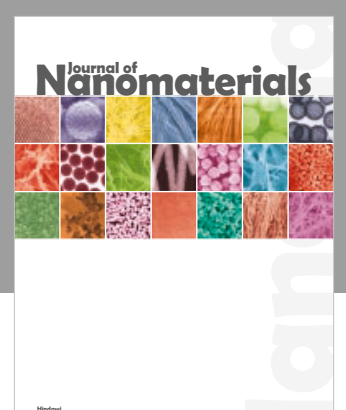

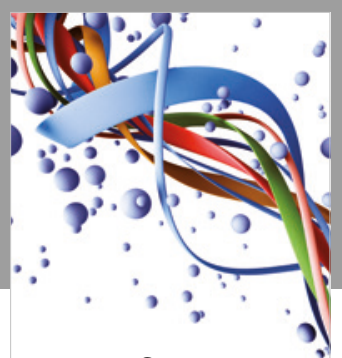

Scientifica

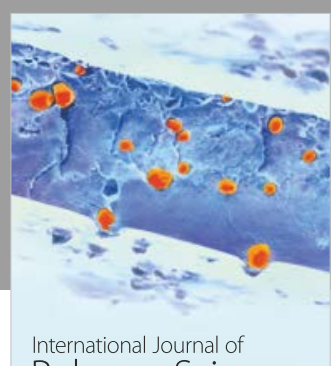

Polymer Science

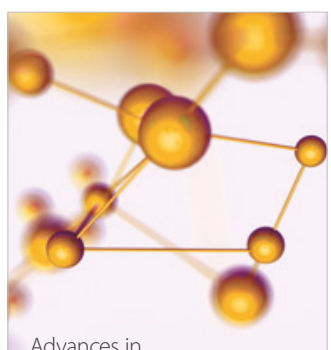

Physical Chemistry
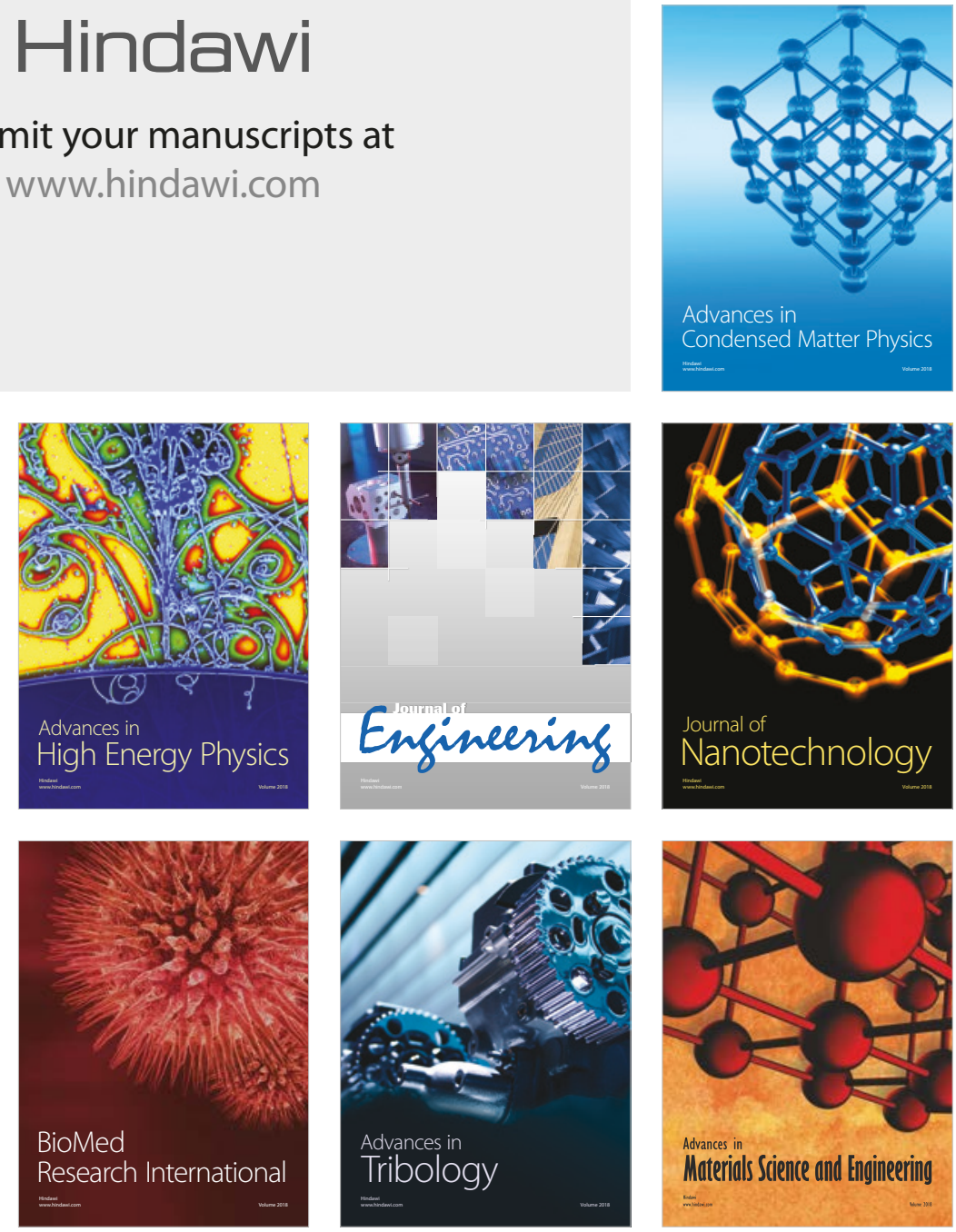